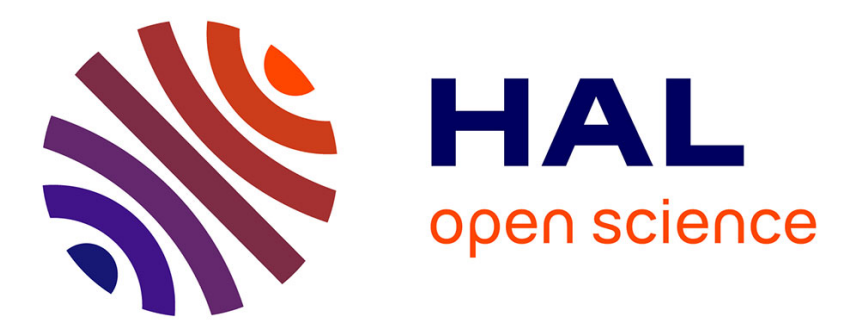

\title{
Taking residual stresses into account in low-cycle fatigue design using the adjustable localisation operator method
}

\author{
Bruno Levieil, Cédric Doudard, David Thevenet, Florent Bridier, Anthony
}

Ezanno, Sylvain Calloch

\section{- To cite this version:}

Bruno Levieil, Cédric Doudard, David Thevenet, Florent Bridier, Anthony Ezanno, et al.. Taking residual stresses into account in low-cycle fatigue design using the adjustable localisation operator method. International Journal of Fatigue, 2021, 150, pp.106322. 10.1016/j.ijfatigue.2021.106322 . hal-03293680

\section{HAL Id: hal-03293680 \\ https://hal.science/hal-03293680}

Submitted on 10 Sep 2021

HAL is a multi-disciplinary open access archive for the deposit and dissemination of scientific research documents, whether they are published or not. The documents may come from teaching and research institutions in France or abroad, or from public or private research centers.
L'archive ouverte pluridisciplinaire HAL, est destinée au dépôt et à la diffusion de documents scientifiques de niveau recherche, publiés ou non, émanant des établissements d'enseignement et de recherche français ou étrangers, des laboratoires publics ou privés. 


\title{
Taking residual stresses into account in low-cycle fatigue
}

\section{design using the adjustable localisation operator method}

\author{
Bruno LEVIEIL ${ }^{1 *}$, Cédric DOUDARD ${ }^{1}$, David THEVENET ${ }^{1}$, Florent BRIDIER ${ }^{2}$, Anthony EZANNO³, \\ Sylvain CALLOCH ${ }^{1}$ \\ ${ }^{1}$ ENSTA Bretagne, UMR CNRS 6027, IRDL, F-29200, Brest, France \\ ${ }^{2}$ Naval Group, 40-42 rue du docteur Finlay, F-75732, Paris, France \\ ${ }^{3}$ DGA Techniques navales, Avenue de la Tour Royale, BP 40915, 83050 Toulon Cedex, France \\ *corresponding author: bruno.levieil@ensta-bretagne.org
}

Keywords: plastic zone; simplified method; notches; load ratio; residual stresses;

\section{Highlights}

- Specimens with different initial stress states are subjected to low-cycle fatigue

- Repeated compressive and tensile loads are applied to the notched specimens

- No effect of negative mean stress vs zero mean stress was found

- The adjustable localisation operator is used to predict stress-strain cyclic curves

- A modification of Morrow's criterion is used to account for positive mean stress

\begin{abstract}
This paper assesses the ability of the Adjustable Localisation Operator (ALO) method to predict the influence of residual stresses on the fatigue behaviour of notched components. Different initial residual stress states are introduced into notched specimens, which are then tested under cyclic loadings in a fatigue range of $10^{3}$ to $10^{5}$ cycles. Experimental comparisons with initially stress-free specimens have shown how tensile residual stresses reduce fatigue life under repeated compressive loading while compressive residual stresses increase fatigue life under repeated tensile loading.

Finite Element Analysis (FEA) and ALO method predictions of changes in residual stress are compared to experimental measurements beforehand to assess fatigue life predictions. A modified version of Morrow's criterion is used to account for the mean stress effect. Results have shown that the ALO method can predict the
\end{abstract}


influence of residual stresses on low-cycle fatigue with the same accuracy as finite element analysis and with a significant reduction in computation time.

\section{Introduction}

Residual stresses are known to influence fatigue life in high-cycle fatigue [1]-[3]. In low-cycle fatigue, it is sometimes considered that they are relaxed due to the relatively high loads and plasticity levels induced. However, several studies have shown an improvement in fatigue life for lifespans as low as 10,000 cycles, using treatments that induce compressive residual stresses such as shot peening [4], [5], cold-hole expansion [6], tensile pre-straining [7] or deep rolling [8]. Although this demonstrates that residual stresses can affect low-cycle fatigue, it must be highlighted that these studies investigated repeated tensile loadings or alternated loadings but that the case of repeated compressive loadings was not studied. If, on the one hand, compressive residual stresses have a positive influence on low-cycle fatigue under repeated tensile loadings, on the other hand, tensile residual stresses could be detrimental to fatigue lifespan under repeated compressive loadings.

Furthermore, the safe design of structures requires the initial stress state influence to be accurately integrated into the design chain. Cyclic calculation can be conducted using finite element analysis in conjunction with an appropriate behaviour law and a fatigue damage criterion. Such calculations remain an expensive and timeconsuming solution, as non-linear finite element requires more computations, and the number of cycles in order to attain a stabilised stress-strain curve further increases this cost. Neuber [9] first proposed a simplified notch calculation method to assess the non-linear cyclic material behaviour at the critical point. A second energy-based method has been proposed by Molski and Glinka [10] which has been proven to be more accurate in the case of a plane strain assumption while Neuber's method is more accurate in the case of a plane stress assumption. Both these methods are not inherently multiaxial and different extensions have been proposed over the past decades with different assumptions [11]-[16]. However, none of these extensions are sufficiently robust to offer satisfying predictions for any multiaxial loading [17]. Other families of simplified methods exist which are based on linearization of the stress strain curve [18], [19], cycle's jump [20], [21], or direct cyclic analysis [22].

An inherently multiaxial method based on a localisation approach such as the one proposed by Eshelby [23] has been developed through the work of different authors [17], [24]-[26]. This method considers that the local plastic zone at the critical point behaves like an inclusion in an elastic matrix. The Adjustable Localisation Operator (ALO) is identified thanks to a quasi-static elastic finite element model and then used for the cyclic analytical calculation of the material stress-strain behaviour at the critical point. The ALO method has been assessed to 
predict fatigue life for initially stress-free specimens in a previous paper [27] that focused on the behaviour law and on the fatigue criterion aspects. The objective of this paper is to assess the ability of the ALO method to take an initial stress-strain state into account.

The first part of this paper deals with the case study and the generation of three initial stress-strain states: a first state without residual stresses to act as a reference; a second state with tensile residual stresses; and a third state with compressive residual stresses. Initial states are validated through FEA and X-Ray Diffraction (XRD) analysis before being tested under repeated tensile or compressive loading. These experiments will be used as validation data for the rest of the study.

In the second part, the ALO method is briefly described before analysing the simulation of the non-standard initial states compared to the FEA predictions.

In the third part, the ALO method predictions under cyclic loading are evaluated in conjunction with FEA to experimental stabilised strain amplitudes. The change in residual stresses is assessed experimentally for some specimens, and compared to FEA and the ALO method's predictions.

The last section deals with the fatigue life predictions with FEA and the ALO method comparing different fatigue life criteria: Manson-Coffin-Basquin, Smith-Watson-Topper and a modified version of Morrow’s criterion.

\section{Experimental influence of residual stresses on the fatigue life of}

\section{notched specimens}

\subsection{Identification of the elastic-plastic behaviour of the material}

The material used for this study is a ferritic high-strength steel. In order to identify its elastic-plastic behaviour, a strain-controlled tensile test is performed with reversed compressive loadings at different chosen plastic strain levels. At each unload, the compressive yield stress is reached and the elastic domain centre and size are measured to identify the kinematic and isotropic hardenings respectively [28]. A sequential identification procedure is used to obtain the hardening parameters [27]. The model used to describe the elastic-plastic behaviour is a mixed hardening model as proposed by Chaboche [29]. It combines various isotropic $\left(\boldsymbol{R}_{\boldsymbol{i}}\right)$ and kinematic $\left(\underline{\boldsymbol{X}_{\boldsymbol{i}}}\right)$ hardenings. The total strain $\underline{\epsilon}$ is the sum of the elastic strain $\underline{\epsilon^{e}}$ and the plastic strain $\underline{\epsilon^{p}}$.

The elastic domain is defined by

$$
\boldsymbol{f}=\boldsymbol{J}_{2}\left(\underline{\sigma}-\sum \underline{X_{i}}\right)-\left(\sum R_{i}+\sigma_{y}\right)=\mathbf{0},
$$


where $\boldsymbol{J}_{\mathbf{2}}($.$) refers to the von Mises equivalent stress and \boldsymbol{\sigma}_{\boldsymbol{y}}$ is the initial tensile yield stress. Chaboche proposed a threshold kinematic hardening [30] expressed as

$$
\underline{\dot{X}_{i}}=\frac{2}{3} C_{i} \underline{\dot{\epsilon}}^{p}-\gamma_{i}\left\langle 1-\frac{X_{\text {lim } i}}{J_{2}\left(\underline{X_{i}}\right)}\right\rangle \underline{X_{i}} \dot{p}
$$

where $\langle$.$\rangle denotes Macaulay brackets, \boldsymbol{X}_{\lim \boldsymbol{i}}$ is the threshold value, $\frac{2}{3} *\left(\boldsymbol{C}_{\boldsymbol{i}} / \boldsymbol{\gamma}_{\boldsymbol{i}}+\boldsymbol{X}_{\lim \boldsymbol{i}}\right)$ is the saturation value in the uniaxial case and $\boldsymbol{\gamma}_{\boldsymbol{i}}$ governs the kinetics of the kinematic hardening. When plasticity is initiated, $\boldsymbol{J}_{\mathbf{2}}\left(\underline{\boldsymbol{X}_{\boldsymbol{i}}}\right)<$ $\boldsymbol{X}_{\text {lim } \boldsymbol{i}}$, the hardening is linear, as in the Prager model [31]. When the hardening reaches the threshold value $\boldsymbol{X}_{\text {lim } \boldsymbol{i}}$, it behaves as a non-linear kinematic hardening in accordance with the Armstrong-Frederick model [32]. The $\boldsymbol{X}_{\text {lim }}$ value is calculated such that the mean stress relaxation curve at $R_{\epsilon}=\frac{\epsilon_{\min }}{\epsilon_{\max }}=0$ is continuous to avoid a discontinuity effect on predicted fatigue curves [33].

The isotropic hardening is adapted from the Voce model [34] to obtain a similar behaviour

$$
\dot{R}_{\boldsymbol{\imath}}=\boldsymbol{b}_{i}\left(\boldsymbol{Q}_{i}-\left\langle\left|\boldsymbol{R}_{\boldsymbol{i}}\right|-\boldsymbol{R}_{\text {lim } i}\right\rangle\right) \dot{\boldsymbol{p}}
$$

where $\boldsymbol{R}_{\text {lim } \boldsymbol{i}}$ is the threshold value, $\boldsymbol{Q}_{\boldsymbol{i}}+\boldsymbol{R}_{\boldsymbol{l i m} \boldsymbol{i}}$ is the saturation value and $\boldsymbol{b}_{\boldsymbol{i}}$ governs the kinetics of the isotropic hardening.

The equivalent cumulative plasticity rate is defined as

$$
\dot{p}=\sqrt{\frac{2}{3} \dot{\epsilon_{p}}: \dot{\epsilon_{p}}}
$$

The plasticity flow is calculated using the normality rule given by

$$
\dot{\epsilon_{p}}=\dot{p} \frac{3}{2} \frac{\left(\underline{\sigma^{D}}-\sum \underline{X_{i}}\right)}{J_{2}\left(\sigma^{D}-\sum \underline{X_{i}}\right)}
$$

with $\underline{\boldsymbol{\sigma}^{\boldsymbol{D}}}$ the deviatoric stress tensor.

The hardening parameters obtained are summarised in Table 1. To protect material confidentiality, in this table and in the rest of this study, stresses are divided by the yield stress $\boldsymbol{\sigma}_{\boldsymbol{y}}$ and strains are divided by the corresponding strain $\boldsymbol{\epsilon}_{\boldsymbol{y}}=\boldsymbol{\sigma}_{\boldsymbol{y}} / \boldsymbol{E}$ where $E$ is the Young's modulus.

\begin{tabular}{|c|c|c|c|c|c|c|c|c|c|}
\hline Parameter & $\mathrm{C}_{\mathbf{1}} / \boldsymbol{\sigma}_{\mathbf{y}}$ & $\boldsymbol{\gamma}_{\mathbf{1}}$ & $\mathrm{C}_{\mathbf{2}} / \boldsymbol{\sigma}_{\mathbf{y}}$ & $\mathrm{C}_{\mathbf{3}} / \boldsymbol{\sigma}_{\mathbf{y}}$ & $\boldsymbol{\gamma}_{\mathbf{3}}$ & $\mathrm{X}_{\lim \mathbf{3}} / \boldsymbol{\sigma}_{\mathbf{y}}$ & $\mathbf{b}_{\mathbf{1}}$ & $\mathbf{Q}_{\mathbf{1}} / \boldsymbol{\sigma}_{\mathbf{y}}$ & $\mathbf{R}_{\lim \mathbf{1}} / \boldsymbol{\sigma}_{\mathbf{y}}$ \\
\hline Value & 85.7 & 5000 & 3.14 & 157 & 1000 & 0.343 & 1000 & -0.157 & 0.343 \\
\hline
\end{tabular}

Table 1: Material behaviour law parameters 


\subsection{Geometry of the notched specimen}

The objective of this study is to predict the fatigue life of specimens under confined plasticity cyclic loadings. For this purpose, the specimens used are designed with two semi-circular notches, as shown in Figure 1. Fatigue loadings are dimensioned to introduce local plasticity around the tip of the notches that act as critical points. Three different initial residual stress states are considered: a first state without residual stresses to act as a reference; a second state with tensile residual stresses; and a third state with compressive residual stresses.

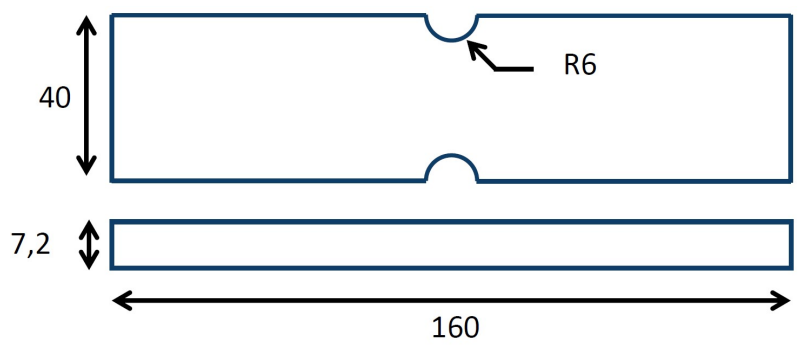

Figure 1: Geometry of a notched specimen (all dimensions in mm)

\subsection{Introduction of three different initial residual stress states}

\subsubsection{Initially residual stress-free state}

The residual stress-free specimens are machined with an electrical-discharge machine from raw laminated sheets. The faces are then grinded to ensure that a minimum level of residual stresses is introduced, and the notches are electro-polished to ensure zero stress at the critical point. These specimens act as the reference state.

\subsubsection{Introduction of tensile residual stresses}

Tensile residual stresses are obtained by bending stress-free specimens as shown in Figure 2. After elastic springback, both tensile and compressive residual stresses are obtained. Since tensile residual stresses are known to reduce fatigue life [35] whereas compressive residual stresses generally increase fatigue life [36], the fatigue life of these specimens is thus driven by the fatigue life of the notch with tensile residual stresses. This assessment has been verified experimentally in this study. 
a) Specimen bending

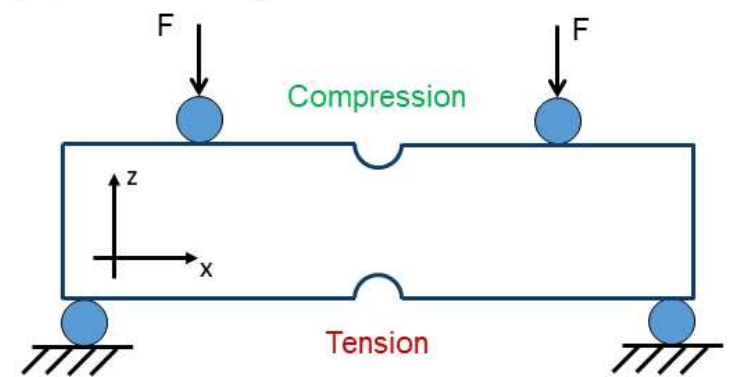

b) After elastic springback

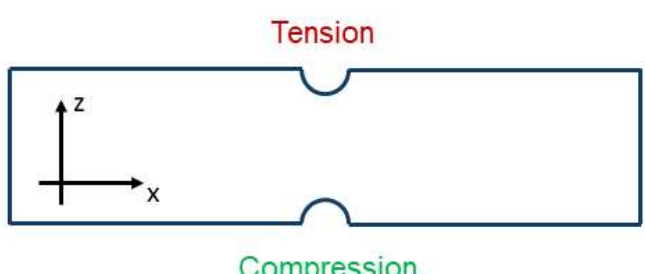

Compression

Figure 2: Introduction of residual stresses by bending stress-free specimens (a) and elastic springback (b)

To predict the initial residual stress state, a finite element analysis of the bending process is used. The $\mathrm{XZ}$ and $\mathrm{YZ}$ symmetry planes are considered to model only a quarter of the whole geometry. Twelve thousand eight-node linear bricks are used to mesh the specimen (C3D8 in Abaqus). Element size is $36 \mu \mathrm{m}$ at the notch tip and under the rollers in $\mathrm{X}$ and $\mathrm{Y}$ directions where the stress gradient is the most important and $360 \mu \mathrm{m}$ in the through-thickness direction Z (20 elements through the total thickness). The mesh around the notch can be seen in figure 15 . The load is applied by means of analytical rigid rollers. A linear friction model is assumed between the specimen and the roller. A friction coefficient of 0.1 is applied, and calibrated using strain measurements around the notch as in a previous study [37]. The simulation results are shown in Figure 3. It can be seen that compressive stresses close to the elastic limit are introduced on one notch whereas the other notch presents an opposite longitudinal residual stress.

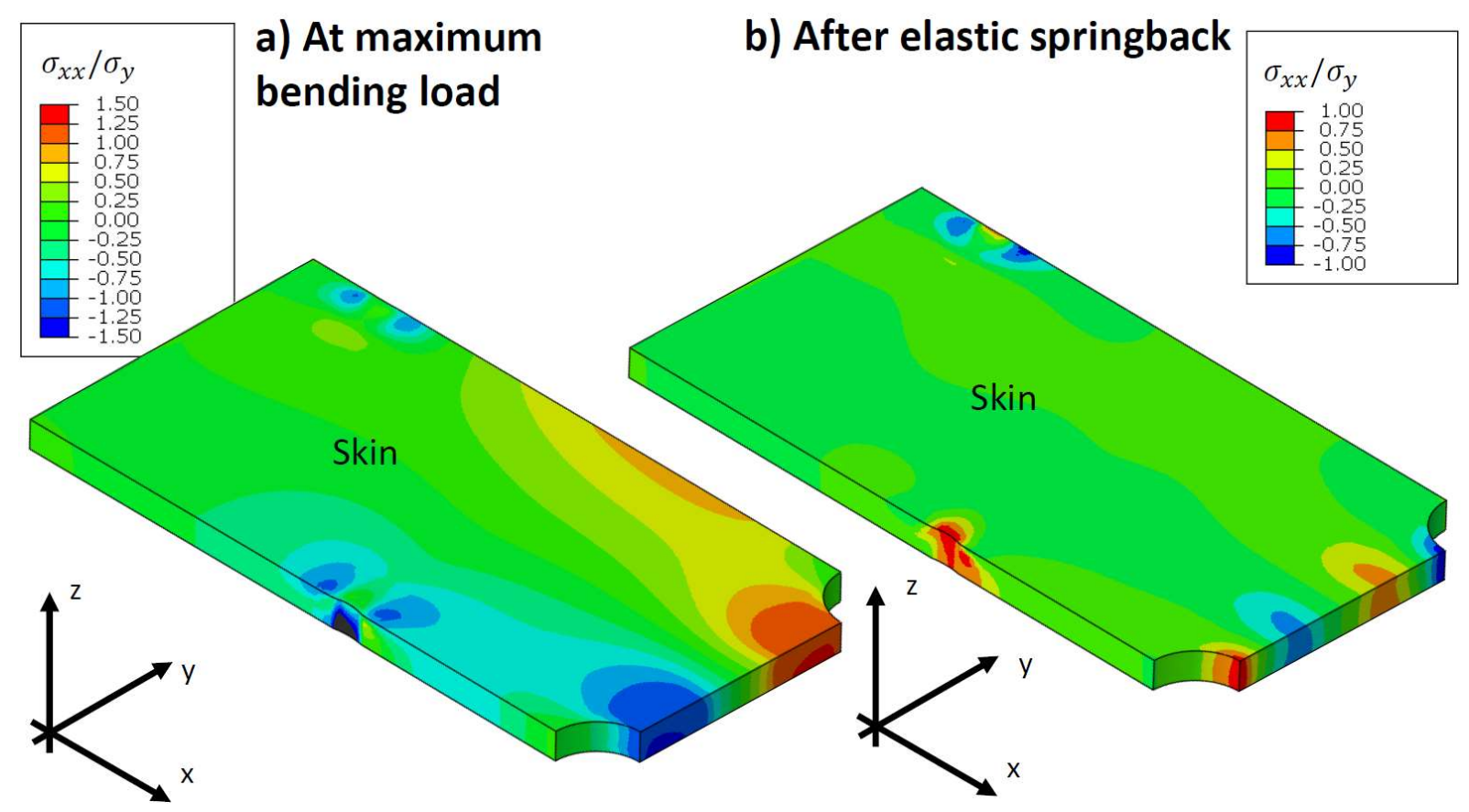

Figure 3: Bending simulation results at maximum bending load (a) and after elastic springback (b). Stress results are divided by the tensile yield stress 


\subsubsection{Introduction of compressive residual stress}

A cold-expansion process was used to introduce compressive residual stresses around the notches. A larger specimen with two $\emptyset 12 \mathrm{~mm}$ holes is machined. A conical pin with a maximum diameter of $12.3 \mathrm{~mm}$ is inserted through each hole. No mandrill or split sleeve is used to make the process simpler. Each pin is made of 35NCD16 quenched steel to ensure that the pin's plastic deformation can be disregarded. This was checked by measuring the pin diameter after cold expansion; no plastic deformation was shown to have occurred. The specimen is then machined, grinded on both faces symmetrically and finally cut with an electrical-discharge machine to obtain the same geometry as for the bent specimens or the stress-free specimens.

a) Cold-hole expansion

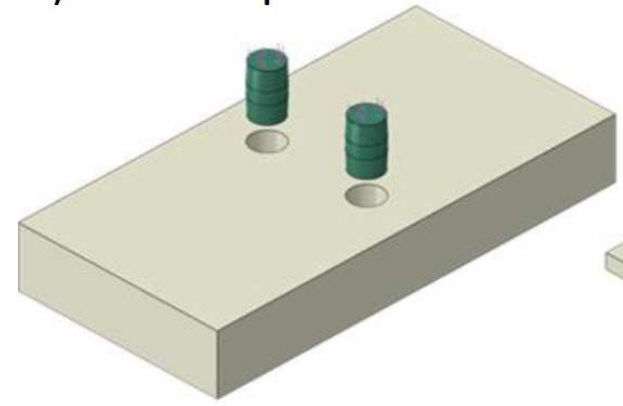

b) Machining

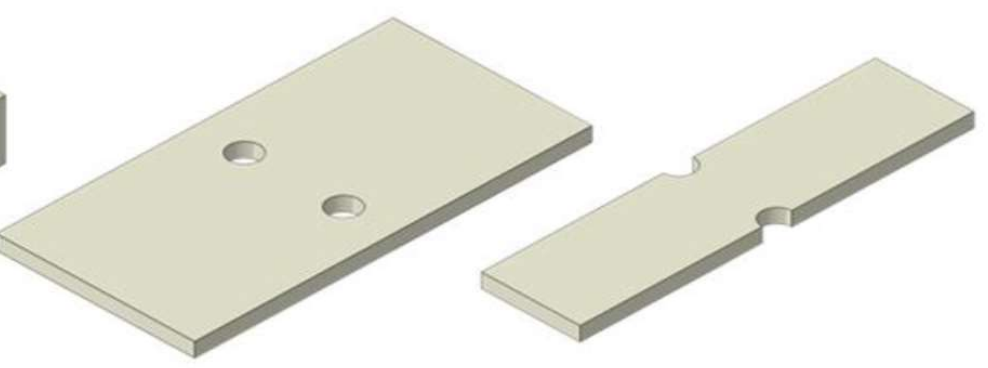

Figure 4: Principle of the cold-expansion process

A 3D finite element analysis of the whole process was performed with the same three steps as in Figure 4. The specimen is meshed with 160,000 8-node linear bricks. The YZ symmetry is considered to reduce the size of the model. The pin's mechanical behaviour is purely elastic. A linear friction coefficient of 0.1 is also applied. In the first step of the analysis, the pin is passed through the hole. In the second and third step, element deletion is used to represent the machining and cutting process, considering that these processes do not introduce significant new residual stresses at the critical point in comparison to those introduced by means of the cold-hole expansion process. The simulation results can be seen in Figure 5. Compressive longitudinal residual stresses close to the tensile yield stress are introduced around the critical point by the cold-expansion process. After machining and cutting, this stress state is partially redistributed but remains at the same level at the critical point. 


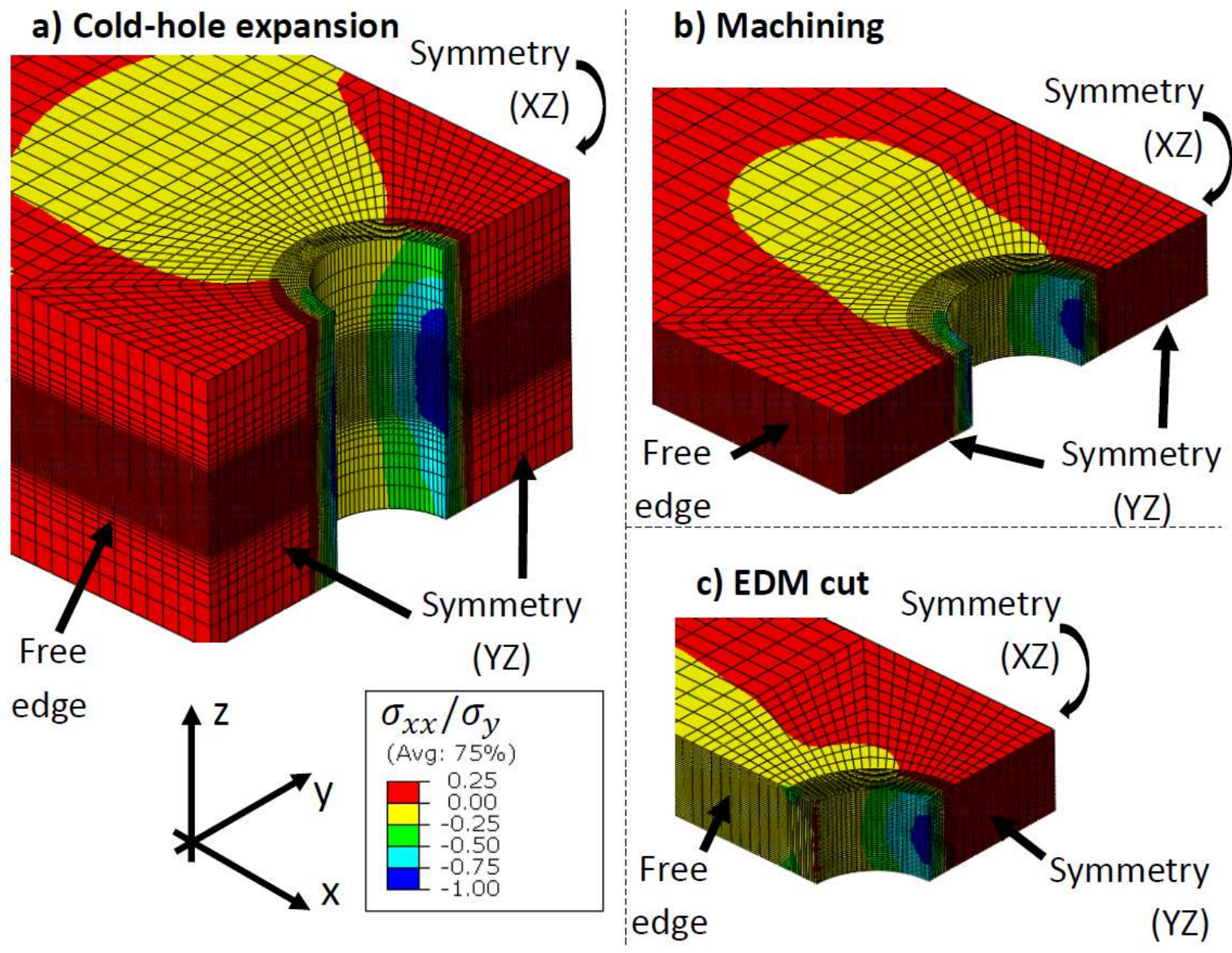

Figure 5: Cartography of the longitudinal stress during the cold-expansion simulation. Stress results are divided by the elastic limit

\subsubsection{Validation of incremental $X$-ray diffraction residual stress}

The three initial residual stress states were measured using incremental X-ray diffraction (IXRD). X-ray diffraction measurements were conducted with a Set-X Elphyse device using the $\sin ^{2} \psi$ method. Elastic radiocristallographic constants are obtained from the literature [38]. After measuring the diffraction peaks at the surface, a layer of material is removed by electro-polishing until a chosen depth is attained. X-ray diffraction is performed again and residual stress analysis can be performed below the original surface. As residual stresses are redistributed due to material removal, a correction method is employed as proposed by Savaria-Bridier-Bocher [39]. The comparison of the residual stress gradient predicted by finite element analysis and the corrected experimental residual stress is shown in Figure 6. The reference zero stress-free state has been measured with a maximum longitudinal stress of $0.05 \sigma_{y}$. It also shows that the value at the surface of the notch of the cold-expanded specimen is around $-0.9 \sigma_{y}$ whereas the value at the surface of the "tensile" notch of the bent specimen is $0.9 \sigma_{y}$. The stress gradient is also similar, with a transition between tension and compression at approximately $2 \mathrm{~mm}$ below the surface of the notch. 
These measurements and the finite element predictions validate the three initial residual stress states that are tested under cyclic repeated loadings.

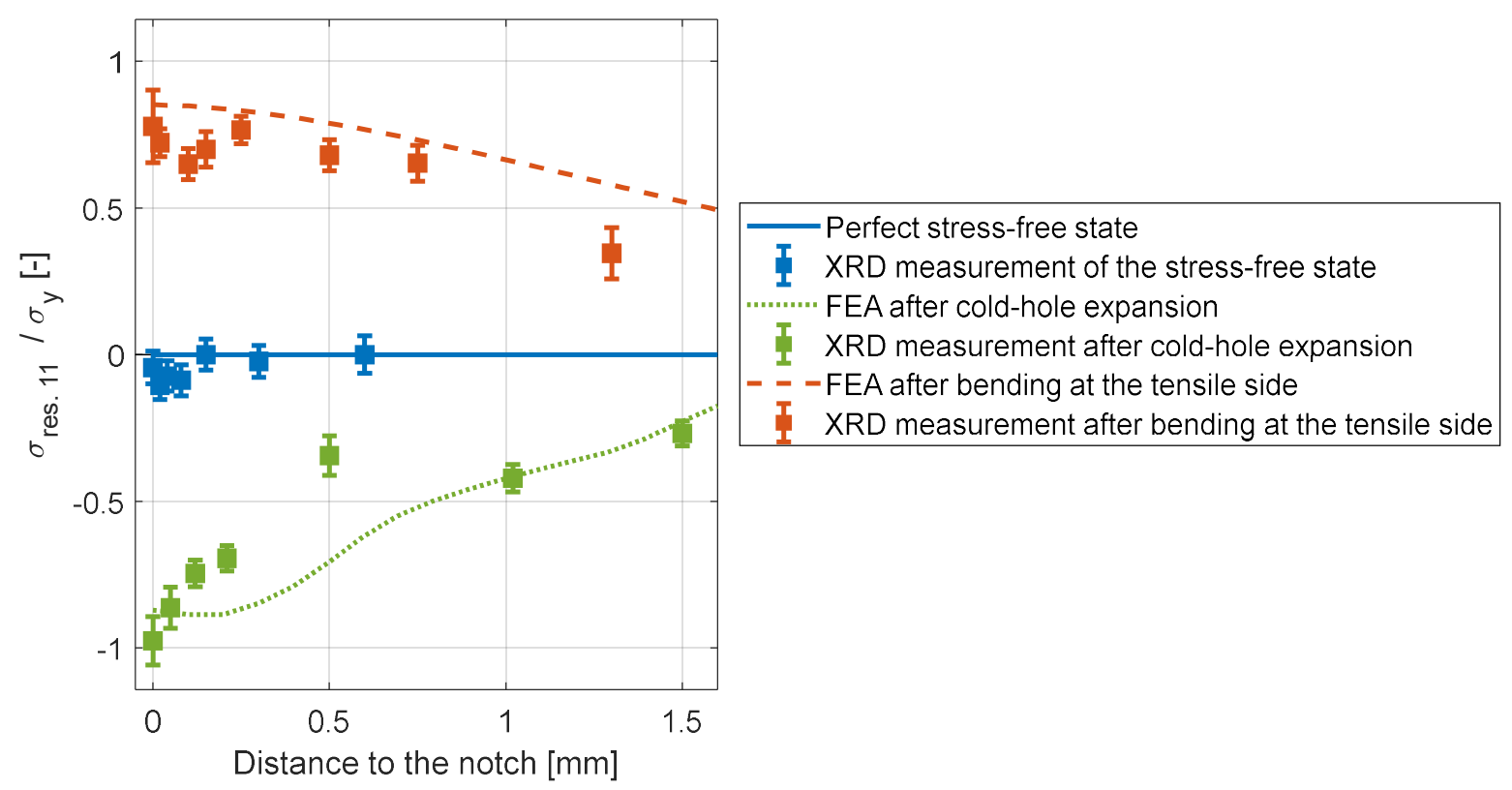

Figure 6: FEA predicted initial residual stress gradients compared to the IXRD corrected measurements

\subsection{Fatigue testing of the notched specimens}

\subsubsection{Experimental set-up}

The notched specimens were tested with an MTS ${ }^{\circledR}$ servo-hydraulic testing machine at a frequency of 2 Hz until initiation. Initiation is detected by means of the alternating current potential drop (ACPD) technique [40] with a Matelec ${ }^{\circledR}$ CGM-7 device. The principle of this device is to supply the tested specimen with an alternating current and to measure the potential on both sides of the notch. When a crack appears, a variation of the potential is measured, as can be seen in Figure 7a). A potential drop of 0.02 volts is chosen as an initiation criterion. To calibrate the corresponding crack length for this ACPD criterion, one of the test is stopped at a potential variation of $0.02 \mathrm{~V}$. This calibration specimen is then immerged in liquid nitrogen to obtain a brittle fracture. Fractographic analysis revealed that the crack is semi-elliptical with a maximum depth of $0.9 \mathrm{~mm}$ and a width of $3.4 \mathrm{~mm}$, as can be seen in Figure 7b). The ACPD criterion of 0.02 volts has been considered for all the fatigue tests in order to determine the number of cycles before initiation. 


\section{a) ACPD signal evolution}

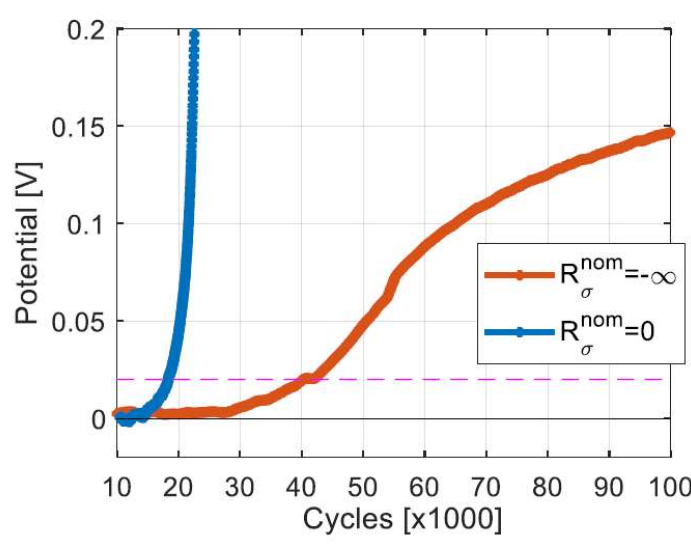

b) Fracture surface at $0.02 \mathrm{~V}$

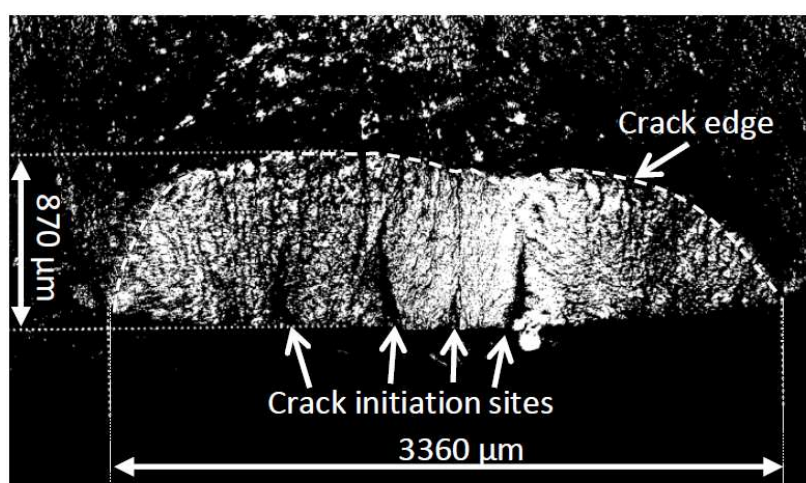

Figure 7: a) Evolution of ACPD signal for specimens under tensile or compressive repeated nominal loading and b) fracture surface obtained for a test stopped at a $0.02 \mathrm{~V}$ variation criterion

\subsubsection{Fatigue results under repeated tensile loadings}

Nine specimens for each of the three initial residual stress states were tested under repeated tensile nominal loadings $R_{\sigma}^{\text {nom }}=\sigma_{\min }^{\text {nom }} / \sigma_{\max }^{\text {nom }}=0$. The fatigue lives obtained, $\mathrm{N}$, are plotted in Figure 8 . It shows that, under repeated tensile loadings corresponding to fatigue lives above $10^{4}$ cycles, specimens with initial compressive residual stresses (denoted as 'RS -' in the rest of the paper) have a higher fatigue life than the reference stress-free specimens (denoted 'RS 0 '). For higher nominal loads, it does not seem to have any significant effect. In the case of initial tensile residual stresses ('RS +'), the initial residual stress states do not seem to have any significant effect, whatever the nominal load level.

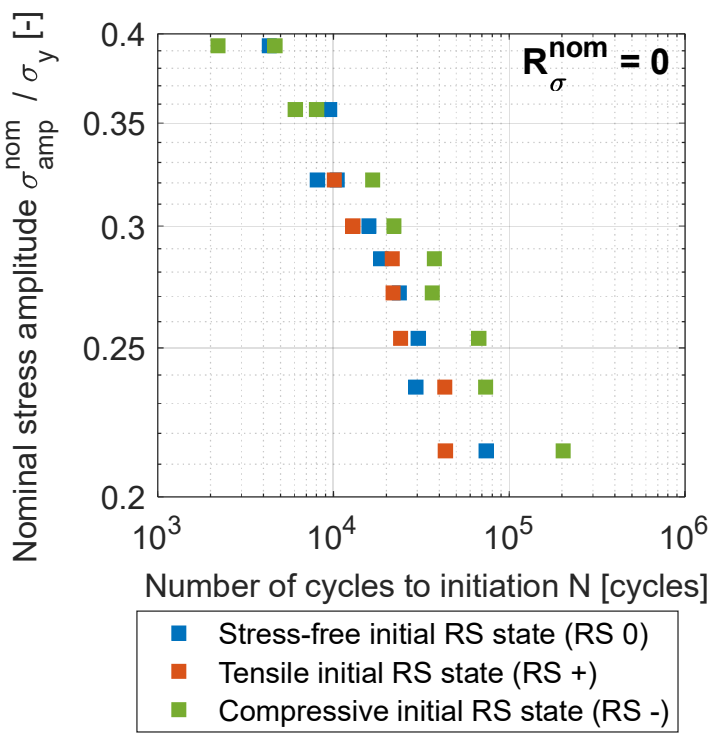

Figure 8: Experimental fatigue life under repeated tensile loadings for the three initial residual stress states 


\subsubsection{Fatigue results under repeated compressive loadings}

Eight reference residual stress-free specimens and seven bent specimens were tested under repeated nominal compressive loadings $\left(R_{\sigma}^{\text {nom }}=-\infty\right)$. The experimental fatigue lives are plotted in Figure 9. All the specimens that were bent prior to fatigue have initiated cracks on the side with tensile residual stresses. For fatigue lives above $10^{4}$ cycles, specimens with tensile initial residual stresses have shorter fatigue lives than those of the residual stress-free reference specimens, which shows the negative influence of the tensile residual stresses under repeated compressive loadings. No significant difference was found for fatigue lives below $10^{4}$ cycles between residual stress-free specimens and tensile initial residual stress specimens.

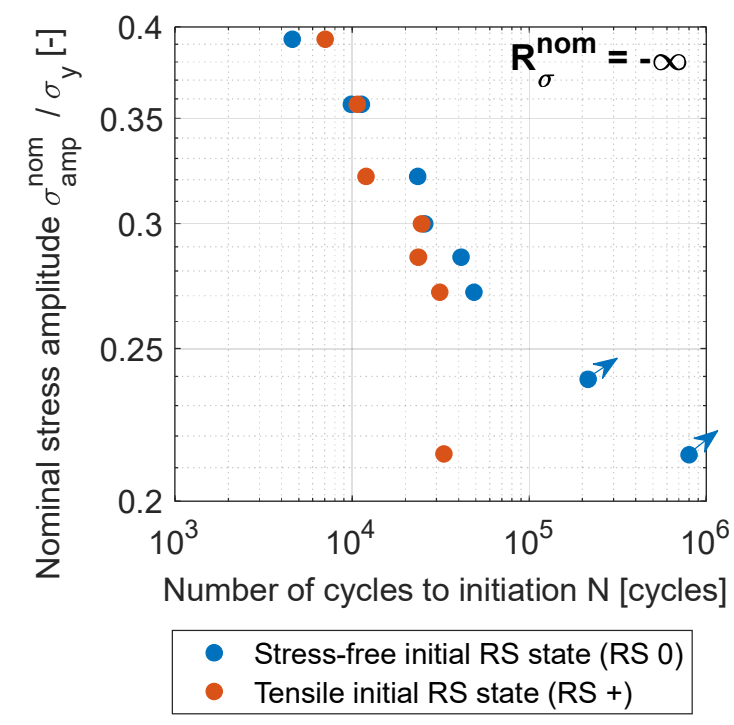

Figure 9: Experimental fatigue life under compressive tensile loadings (arrows indicate unbroken sample)

As a conclusion from the fatigue tests, it appears that if the initial residual stress has the same sign as the repeated cyclic stress, the initial residual stress is observed to have no effect on the fatigue life. If the cyclic stress is opposite to the initial residual stress, then tensile residual stresses reduce the fatigue life, while compressive residual stresses increase the fatigue lives within the range of $10^{4}-10^{5}$ cycles.

Although fatigue life under different load ratios was plotted separately for the sake of clarity, it can be observed that for initially residual stress-free specimens, the load ratio affects fatigue life, with longer fatigue lives observed for specimens subject to repeated compressive loadings. No influence of the load ratio was found in the case of specimens with initial residual stresses. 
In the following sections, the introduction of residual stresses and the cyclic behaviour are modelled using the ALO method in order to predict fatigue lives. FEA is used in parallel to analyse the ability of the ALO method to predict the influence of residual stresses.

\section{Introduction of residual stresses using the adjustable localisation operator method}

\subsection{The adjustable localisation operator method}

The adjustable localisation operator (ALO) method is a local simplified method to predict stress-strain behaviour in confined plasticity such as Neuber's method [9] or the Equivalent Strain Density Energy (ESED) method [10]. Its benefit is in the multiaxial formulation, as no heuristic needs to be made, unlike extensions of Neuber's method or the ESED method [11]-[13], [41], [42]. The method is based on the analogy between the elastic-plastic zone around a notch and a inclusion in an elastic matrix, in a manner similar to Eshelby's problem [23]. It has been developed through the work of different authors [17], [24], [25], [43].

The stress tensor at the critical point, $\underline{\boldsymbol{\sigma}^{\text {loc }}}$, can be related to the nominal stress tensor by

$$
\underline{\dot{\sigma}^{l o c}}=\underline{\underline{K_{T}}} \underline{\underline{\dot{\sigma}^{n o m}}}-\underline{\underline{L}}: \underline{\dot{\epsilon}_{p}^{l o c}}
$$

where $\underline{\boldsymbol{\epsilon}_{p}^{l o c}}$ is the local plastic strain tensor, $\underline{\underline{L}}$ is the fourth-order localisation operator, $\underline{\underline{\boldsymbol{K}_{T}}}$ is the fourth-order elastic stress concentration factor defined as the ratio of the local stress tensor to the nominal stress tensor under an elastic assumption. The dot operator over a letter refers to its time derivative. As the confined plasticity problem is different from Eshelby’s problem, the localisation operator $\underline{\underline{\boldsymbol{L}}}$ differs from Eshelby’s solution.

However, using the free-edge boundary condition and assuming $\overrightarrow{\boldsymbol{x}_{\mathbf{2}}}$ is the normal direction in relation to the free surface, the localisation operator can be simplified as

$$
\underline{L}=2 G(1-\beta)\left(\begin{array}{cccccc}
Z_{1111} & 0 & Z_{1133} & 0 & 0 & 0 \\
0 & 0 & 0 & 0 & 0 & 0 \\
Z_{1133} & 0 & Z_{3333} & 0 & 0 & 0 \\
0 & 0 & 0 & 0 & 0 & 0 \\
0 & 0 & 0 & 0 & Z_{1313} & 0 \\
0 & 0 & 0 & 0 & 0 & 0
\end{array}\right)
$$

in Voigt notation, where $\boldsymbol{G}$ is the shear modulus, $\boldsymbol{v}$ is the Poisson's ratio of the material and 


$$
\beta=\frac{2(4-5 v)}{15(1-v)}
$$

In addition, if independence from any rotation around the axis $\left(\overrightarrow{\boldsymbol{x}_{\mathbf{2}}}\right)$ is assumed, the following relationship can be obtained

$$
Z_{3333}=Z_{1111} \text { and } Z_{1313}=\frac{1}{2}\left(Z_{1111}-Z_{1133}\right) .
$$

As such, the complete determination of the localisation operator requires the estimation of $Z_{1111}$ and $Z_{1133}$.

The value of these parameters for a particular problem can be obtained by formulating two assumptions.

First, it is proposed to consider that the plastic zone behaves similarly to an hemispheric inclusion at the surface of a matrix [24], [25] for which the numerical solution gives $Z_{1111}=\mathbf{1 . 7 9}$.

Then, to evaluate the value of $\boldsymbol{Z}_{\mathbf{1 1 3 3}}$, it is assumed that the amount of plasticity is sufficient to consider that $\left\|\underline{\underline{\epsilon_{p}^{l o c}}}\right\| \gg\left\|\underline{\underline{\epsilon_{e}^{l o c}}}\right\|$, and thus

$$
\underline{\sigma^{l o c}} \propto \underline{\underline{K_{T}^{v=0.5}}}: \underline{\underline{\sigma^{n o m}}}
$$

where $\boldsymbol{K}_{T}^{\boldsymbol{v}=\mathbf{0 . 5}}$ is the fourth-order elastic stress concentration factor defined as the ratio of the local stress tensor to the nominal stress tensor under an elastic assumption by considering $\boldsymbol{v}=\mathbf{0 . 5}$. The 0.5 value is used to represent the isochorous plastic behaviour. To satisfy the previous proportional equation, $\boldsymbol{Z}_{\mathbf{1 1 3 3}}$ must verify [27]

$$
\frac{Z_{1133}}{Z_{1111}}=\frac{\frac{K_{T 3311} K_{T 3311}^{\nu=0.5}}{2}-\frac{K_{T 1111} K_{T 1111}^{\nu=0.5}}{2}+K_{T 1111} K_{T 3311}^{\nu=0.5}-K_{T 3311} K_{T 1111}^{\nu=0.5}}{K_{T 3311} K_{T 3311}^{\nu=0.5}-K_{T 1111} K_{T 1111}^{\nu=0.5}+\frac{K_{T 1111} K_{T 3311}^{\nu=0.5}}{2}-\frac{K_{T 3311} K_{T 111}^{v=0.5}}{2}}
$$

The localisation operator is fully identified using the fourth-order elastic stress concentration tensors obtained with two FEAs of the problem. The first uses the real material Poisson's coefficient, which is 0.3 in this study. The second analysis uses a Poisson's coefficient of 0.495 , as 0.5 would lead to numerical issues in the FEA software. Once the localisation operator is identified, the cyclic behaviour can be calculated by means of a radial return mapping integration scheme. This enables all non-linear behaviour laws, including viscous effects [44], to be used. The rest of the procedure (visually summarised in Figure 10) is identical to the classic FEA design method. From the stabilised multiaxial stress-strain hysteresis, the local equivalent strain is calculated and used as an input in the fatigue life criteria that are presented in the last section. 


\begin{tabular}{|c|c|c|c|c|}
\hline $\begin{array}{c}\text { Two elastic } \\
\text { FEA of the } \\
\text { whole } \\
\text { structure } \\
-v=0.3 \\
-v=0.5\end{array}$ & $\begin{array}{c}\text { Calculation of } \\
\text { the } \\
\text { localisation } \\
\text { operator } \underline{\underline{L}}\end{array}$ & $\begin{array}{c}\text { Analytical } \\
\text { cyclic } \\
\text { calculation of } \\
\text { the elasto- } \\
\text { plastic } \\
\text { behaviour at } \\
\text { the critical } \\
\text { point }\end{array}$ & $\begin{array}{l}\text { Calculation of } \\
\text { the equivalent } \\
\text { stabilised } \\
\text { parameters of } \\
\text { the fatigue } \\
\text { criterion }\end{array}$ & $\begin{array}{c}\text { Fatigue life } \\
\text { prediction } \\
\text { using a } \\
\text { fatigue } \\
\text { criterion }\end{array}$ \\
\hline
\end{tabular}

Figure 10: Fatigue life design methodology using the ALO method

\subsection{Introduction of residual stress with the ALO method}

The ALO method can be used to simulate the introduction of residual stresses. The simplest way to do so is to begin the analytical calculation from a non-zero stress. This is relevant in the case of residual thermal stresses such as welding residual stresses, where the post-welding material behaviour can be identified by means of a thermally treated specimen used to simulate the heat-affected zone. In the case of mechanically induced stresses, the introduction of residual stresses occurs as a result of a plastic deformation process that modifies the material hardenings and can influence fatigue life. To account for this effect, the ALO method is used to simulate a macroscopic loading that induces a local elastic-plastic loading-unloading at the critical point prior to fatigue. In the current study, the macroscopic load value is known and could be used directly in the ALO method to obtain the initial residual stress state. However, it is not always easy to obtain this information, as for example, in shot peening or welding processes. To highlight the method capability to give satisfying results in both cases, a different procedure is used in this study where only the measured local residual stress is needed. In this procedure, the value of the macroscopic load is incrementally raised until the desired experimentally measured longitudinal residual stress is obtained $\left( \pm 0.9 \sigma_{y}\right)$

For comparison purposes, this work is also carried out through FEA, and the results are plotted in Figure 11. In the longitudinal direction, the stresses are very similar, although strain is underestimated with the ALO method in comparison to FEA. In the through-thickness direction, strain and stresses are underestimated with the ALO method. This can be explained by the fact that a high level of plasticity is introduced together with residual stresses, as shown in Figure 12, which implies that the confined plasticity assumption is not perfectly verified. This high plasticity level $\left(>4 \epsilon_{y}\right)$ also implies that the non-linear part of the hardenings is almost saturated, and therefore that the yield surface predicted with FEA and the ALO method are very similar. 

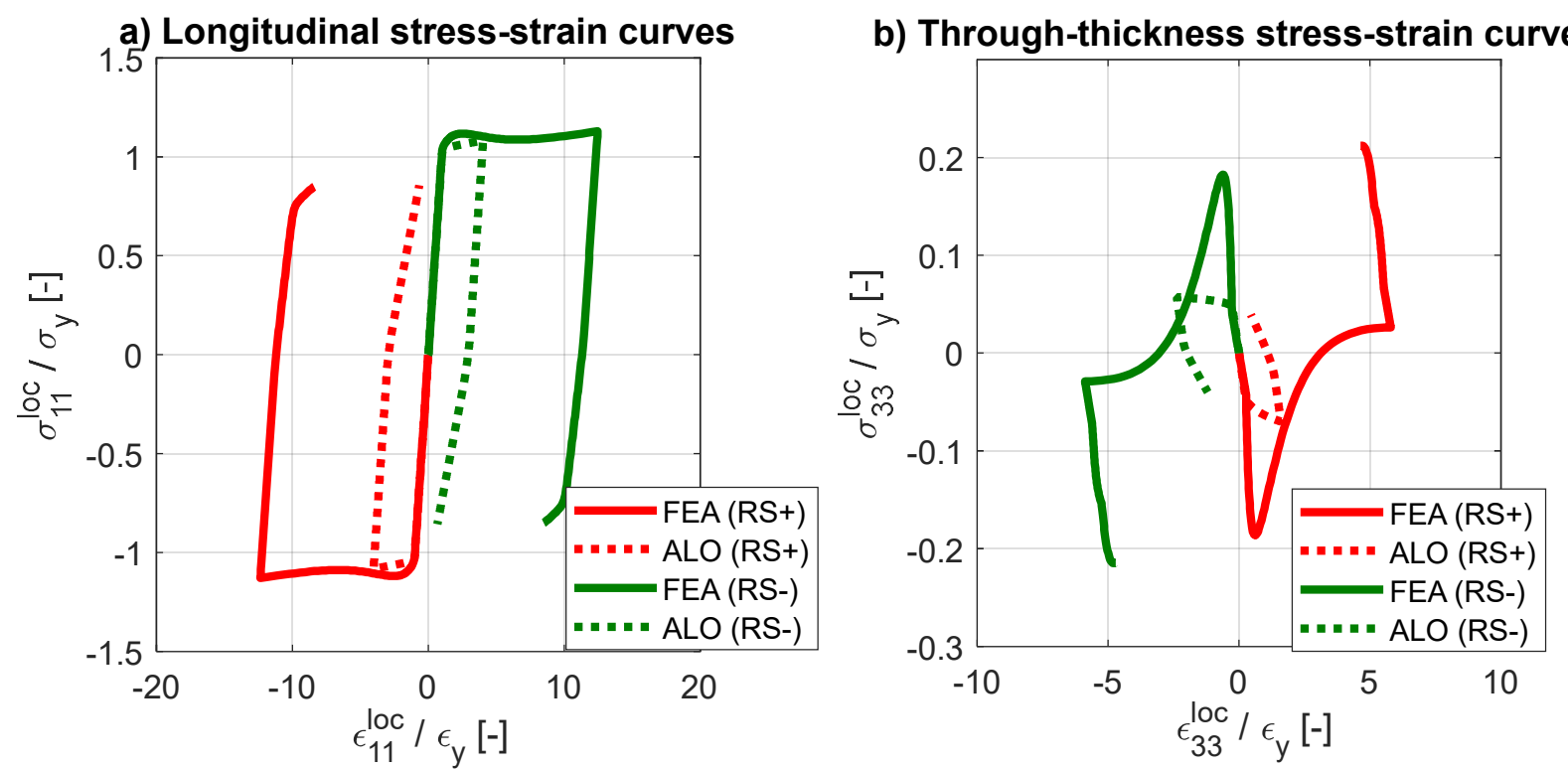

Figure 11: Stress-strain curves at the critical point during the introduction of residual stress in the (a) longitudinal and (b) through-thickness directions

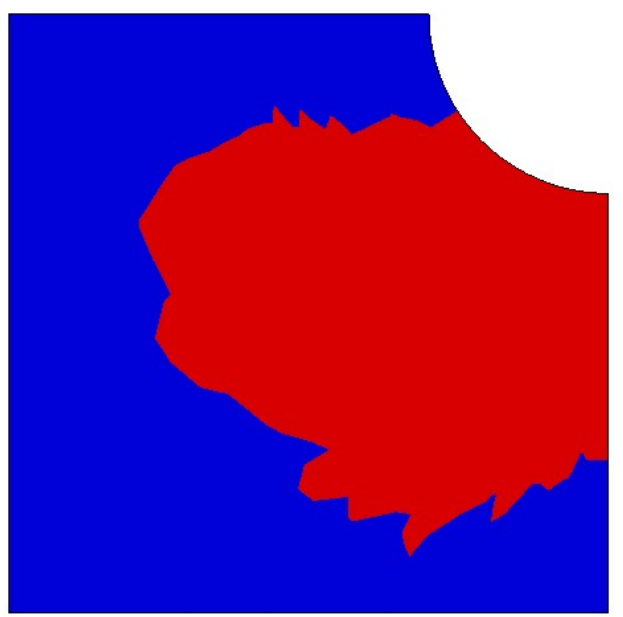

Figure 12: Yielding zone around the notch during bending for the introduction of residual stresses

\section{Cyclic calculations using the ALO method}

\subsection{ALO method prediction of the initial state influence on the cyclic behaviour}

The ALO method is used to simulate the cyclic behaviour at the critical points. For this purpose, fifty cycles are simulated in order to obtain a satisfactory stabilisation of stresses and strains. As the loads are in the low-cycle fatigue range, confined plasticity occurs around the notches and stresses and strains change quickly in the first tens of cycles.

Figure 13 shows the ALO method prediction of the change in longitudinal stress-strain curves evolution at the critical point under an intermediate level of repeated tensile nominal stress $\left(0.29 \sigma_{y}\right)$. It can be observed that the 
predicted cyclic behaviour is very similar between specimens without tensile stresses ('RS 0') and those with initial tensile stresses ('RS +'). This explains why, under repeated tensile loads, no difference in fatigue life is found experimentally between specimens without initial residual stresses and those with initial residual tensile stresses.

Indeed, when the specimen contains initial residual stresses due to a mechanical load, the cyclic loading path starts at the yield surface. Any load of the same sign will induce immediate plasticity, and the loading path becomes parallel to the reference stress-free specimens ('RS 0') once the first maximum load has been reached.

For specimens with compressive residual stresses, Figure 13 shows that the stress-strain curves are stabilised starting from the first cycle, as the plasticity increment is relatively low in comparison to the other initial states. Therefore, the mean stress remains negative whereas it was positive for the other stress-strain states, which explains why those specimens ('RS -') have a longer lifespan.

The opposite conclusions can be drawn with compressive repeated loading, as the material behaviour equations are symmetrical. Immediate yielding at the critical point occurs for 'RS -' specimens subjected to repeated compressive loadings inducing significant levels of plasticity, which implies that, after the first maximum load (as an absolute value), the stress-strain curve of the 'RS -' specimens will become parallel to the reference specimens with identical mean stress. For the 'RS +' specimens, the initial tensile stress will delay yielding at the critical point and induces rapid accommodation. This implies that the mean tensile stress will not be relaxed and that cracks will be initiated earlier in 'RS +' specimens than in the two others.

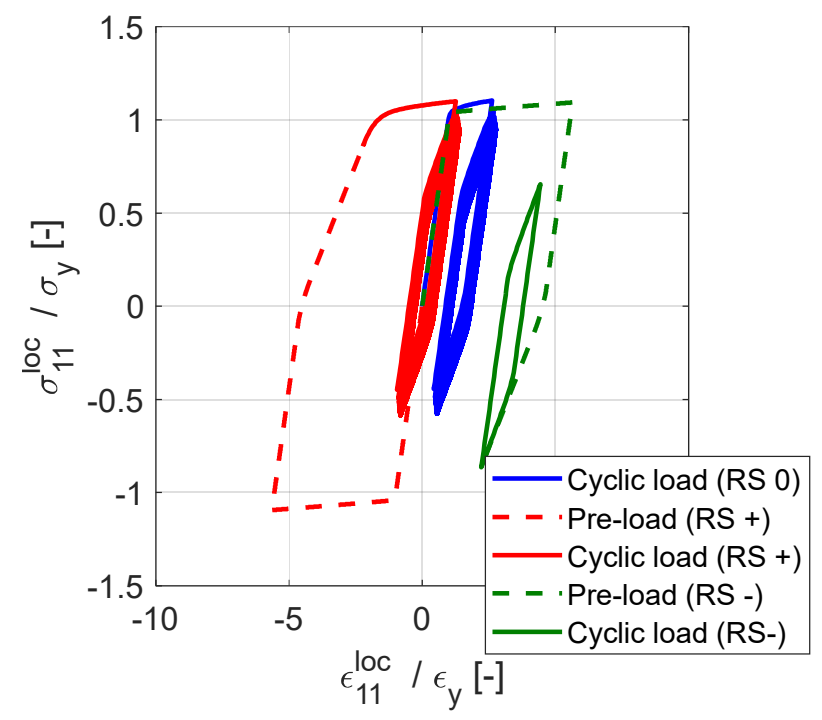

Figure 13: Introduction of residual stresses and cyclic loading for the three initial states at $R_{\sigma}^{\text {nom }}=\mathbf{0}$ at a nominal stress amplitude of $0.29 \sigma_{y}$ predicted with the ALO method 


\subsection{Comparison of the predicted cyclic response with experimental data}

\subsubsection{Stabilised strain amplitude}

The first-order variable for the fatigue life criteria in question, as detailed in section 4.1.1, is the strain amplitude. To validate the ability of the ALO method to predict this value, strain gauges were glued to the bottom of the notch during the test to record longitudinal strains. Relatively small strain gauges (KYOWA ${ }^{\circledR}$ KFG-02-120-C1-11) were used with a $2 \mathrm{~mm}$ gauge volume to obtain measurements in a zone where strains are uniform.

Results are plotted in Figure 14 and three observations must be highlighted.

- The predicted local strain amplitudes are slightly overestimated using FEA or the ALO method in comparison to experimental data. This may be due to either a long-term softening effect that cannot be predicted with the behaviour law or a variation in the strain under the strain gauge.

- The second observation is that FEA and the ALO method perfectly correlate for nominal stress amplitudes below $0.35 \sigma_{y}$ but start to diverge above this limit, because plasticity can no longer be considered as being confined for these high stress levels, as shown in Figure 15.

- The third observation is that neither the initial residual stress state nor the load ratio affects the strain amplitude, as the values only depend on the applied nominal stress. This last observation highlights the fact that the influence of load ratio or residual stress on fatigue life must be incorporated into the model through another variable.

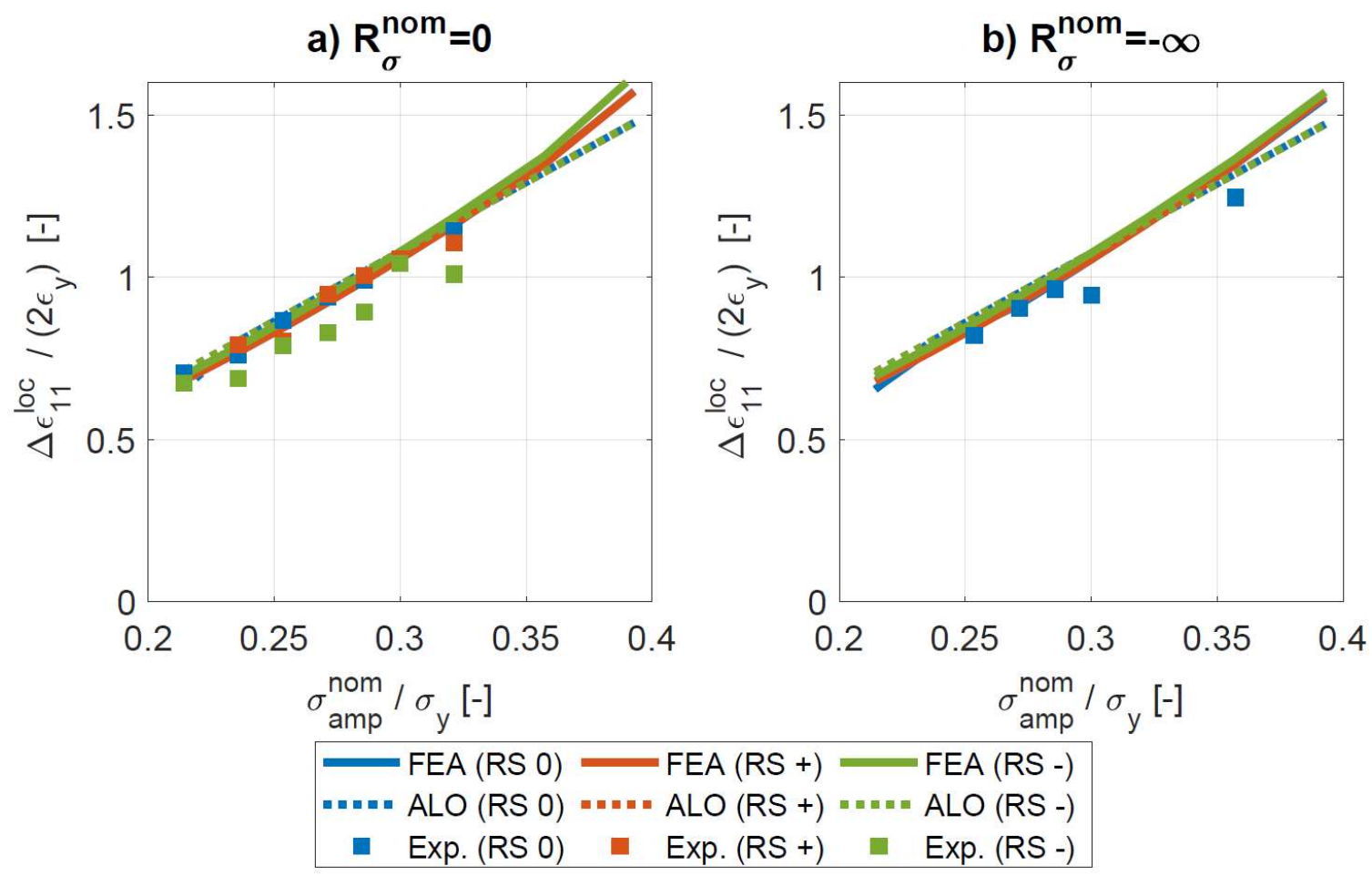

Figure 14: Longitudinal strain amplitudes for the three initial states at $\boldsymbol{R}_{\sigma}^{\text {nom }}=\mathbf{0}$ (a) and at $\boldsymbol{R}_{\sigma}^{\text {nom }}=-\infty$ (b) 


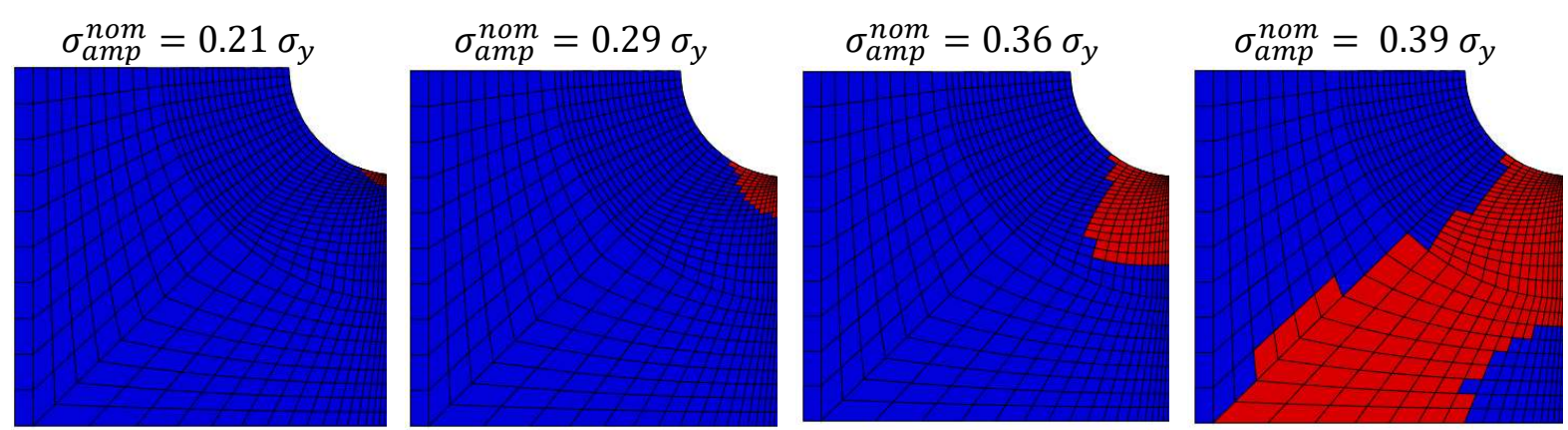

Figure 15: Yielding zone around the notch for four increasing load levels for initially stress-free specimens

\subsubsection{Change in residual stress}

To obtain intermediate experimental validation data - before the assessment of fatigue life predictions vs. experimental fatigue life - some tests were interrupted after 1 and 1000 cycles in order to measure the residual longitudinal stress. Results are plotted in Figure 16 together with FEA and ALO method predictions. Several observations can be made:

- The change in stresses obtained with the ALO method and FEA are very similar: the maximum difference is obtained after the first cycle where the difference between predictions is roughly $0.1 \sigma_{y}$; after stabilisation (50 cycles), the maximum difference is $0.06 \sigma_{y}$ and is obtained for the highest load level $\left(0.36 \sigma_{y}\right)$ for which the confined-plasticity assumption is not verified.

- The trends observed numerically and experimentally are similar. When the cyclic load increases, the residual stresses converge to the same values whatever the initial state. This explains why the initial stress state was experimentally observed to have no effect for the highest loads.

The ability of the model to predict changes in residual stresses under cyclic loading is a preliminary result for the ability of the fatigue life model. 

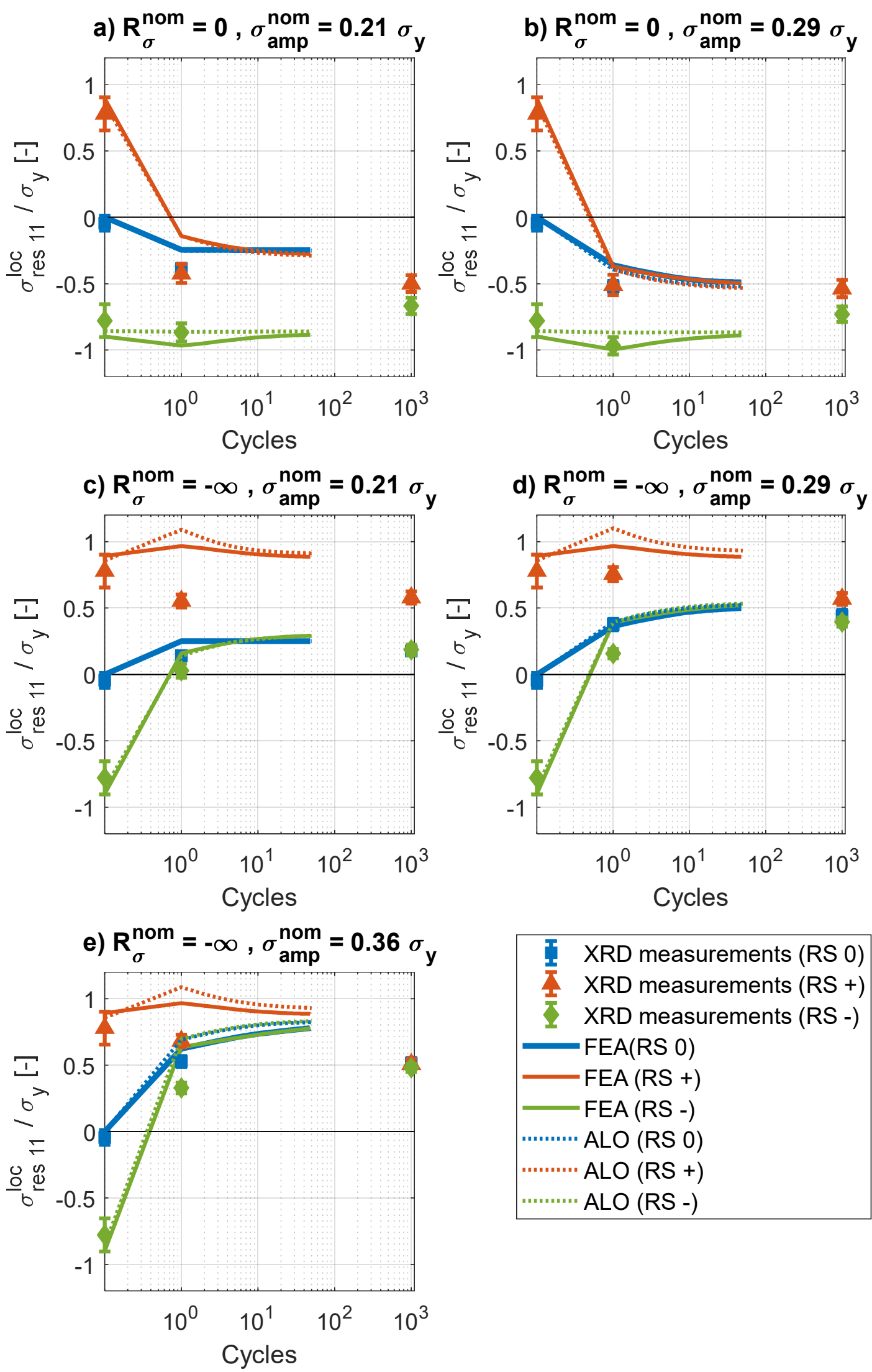

Figure 16 : Experimental changes in residual stresses during cyclic loading compared to the ALO method and FEA for five cases: a) $R_{\sigma}^{n o m}=0$ and $\sigma_{a m p}^{n o m}=0.21 \sigma_{y}$, b) $R_{\sigma}^{\text {nom }}=0$ and $\left.\sigma_{a m p}^{\text {nom }}=0.29 \sigma_{y}, \mathrm{c}\right) R_{\sigma}^{\text {nom }}=$ $-\infty$ and $\sigma_{a m p}^{\text {nom }}=0.21 \sigma_{y}$, d) $R_{\sigma}^{\text {nom }}=-\infty$ and $\sigma_{\text {amp }}^{\text {nom }}=0.29 \sigma_{y} R_{\sigma}^{\text {nom }}=-\infty$ and $\sigma_{a m p}^{\text {nom }}=0.36$ 


\section{Fatigue life calculation using simplified methods}

\subsubsection{Fatigue criteria formulation}

Three fatigue criteria are compared in this study. The first one is the Manson-Coffin-Basquin (MCB) criterion [45], [46] expressed as

$$
\frac{\Delta \epsilon}{2}=\frac{\sigma_{f}^{\prime}}{E}(2 N)^{b}+\epsilon_{f}^{\prime}(2 N)^{c}
$$

where $N$ is the number of cycles to initiation and $\Delta \epsilon$ is the strain range. Three of the material-dependent parameters were estimated using the universal slopes method [45]: $b=-0.12, c=-0.6$ and $\sigma_{f}^{\prime}=1.9 \sigma_{u}$ where $\sigma_{u}$ is the ultimate tensile stress. The last coefficient $\epsilon_{f}^{\prime}$ was calibrated on one fatigue test performed on an initially stressfree notched specimen with an intermediate repeated tensile loading $\left(\sigma_{a}=0.29 \sigma_{y}\right)$. Although this procedure requires one fatigue life experiment to be performed on the tested structure, it intrinsically compensates for the critical-volume effect [47], [48] that exists between smooth calibration samples and notched specimens.

The MCB criterion only takes into account the strain amplitude. As the nominal load ratio does not affect the predicted strain amplitude, it is clear that MCB cannot predict the fatigue life variations observed experimentally for the different initial residual stress configurations and for the different loading directions.

To do so, using the same material parameters and identification basis, the Smith-Watson-Topper (SWT) criterion [49] and Morrow's criterion [50] can be used.

SWT criterion uses the maximum stress $\boldsymbol{\sigma}_{\max }$ to introduce the load ratio effect in the MCB criterion, expressed as

$$
\frac{\Delta \varepsilon}{2}=\left[\frac{\sigma_{f}^{\prime 2}}{E}(2 N)^{2 b}+\sigma_{f}^{\prime} \varepsilon_{f}^{\prime}(2 N)^{b+c}\right] \frac{1}{\sigma_{\max }}
$$

Morrow's criterion introduces the mean stress value in the MCB equation to account for the load ratio effect. It is used in a modified version written as

$$
\frac{\Delta \varepsilon}{2}=\frac{\sigma_{f}^{\prime}-\left\langle\sigma_{m}\right\rangle}{E}(2 N)^{b}+\varepsilon_{f}^{\prime}(2 N)^{c}
$$

where $\langle$.$\rangle denotes Macaulay brackets, i.e. the positive part of a scalar. This modified version was proposed in a$ previous paper [27] and the reasons for it are based on experimental observations of simple cylindrical smooth specimens under different load ratios having demonstrated that negative mean stress does not have any influence on fatigue life for this material. 


\subsubsection{Equivalent multiaxial formulation of fatigue life criteria}

The three fatigue criteria are originally written in a scalar form and must be adapted to multiaxial stress-strain states. For this purpose, an equivalent scalar parameter approach for stress and strain tensors is adopted.

The equivalent plastic strain amplitude $\Delta \boldsymbol{\epsilon}_{\boldsymbol{e q}}$ is calculated as

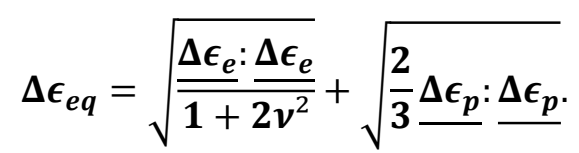

This approach can be easily implemented numerically and is equivalent to the classic scalar approach in the case of a uniaxial stress state.

The equivalent maximum stress $\boldsymbol{\sigma}_{\max } \boldsymbol{e q}$ is calculated with the second invariant of the deviatoric stress tensor (i.e. von Mises stress) for the application of the Smith-Watson-Topper criterion

$$
\sigma_{\text {max eq }}=J_{2}\left(\underline{\sigma_{\text {max }}}\right)=\sqrt{\frac{3}{2} \underline{\sigma_{\text {max }}^{D}}: \underline{\sigma_{\text {max }}^{D}}}
$$

To conserve the mean stress sign in Morrow's criterion, the first invariant of the mean stress tensor $\boldsymbol{\sigma}_{\boldsymbol{m}}$ is preferred for calculating Morrow's criterion

$$
\sigma_{m e q}=\operatorname{tr}\left(\underline{\sigma_{m}}\right)
$$

The comparison of the predicted equivalent mean stress with FEA and the ALO method can be seen in Figure 17. The two prediction methods have very similar trends. At $R_{\sigma}^{\text {nom }}=0$, it can be noted 'RS +' and 'RS 0' specimens have the same stabilised mean tensile stress whereas 'RS -' specimens have an opposite negative mean stress, which explains the increase in fatigue life for these particular specimens.

Under repeated compressive loads, 'RS -' specimens have the same stabilised negative mean stress as the reference 'RS 0' specimen while the 'RS +' specimens have a stabilised mean tensile stress that explains the reduction in fatigue life. 


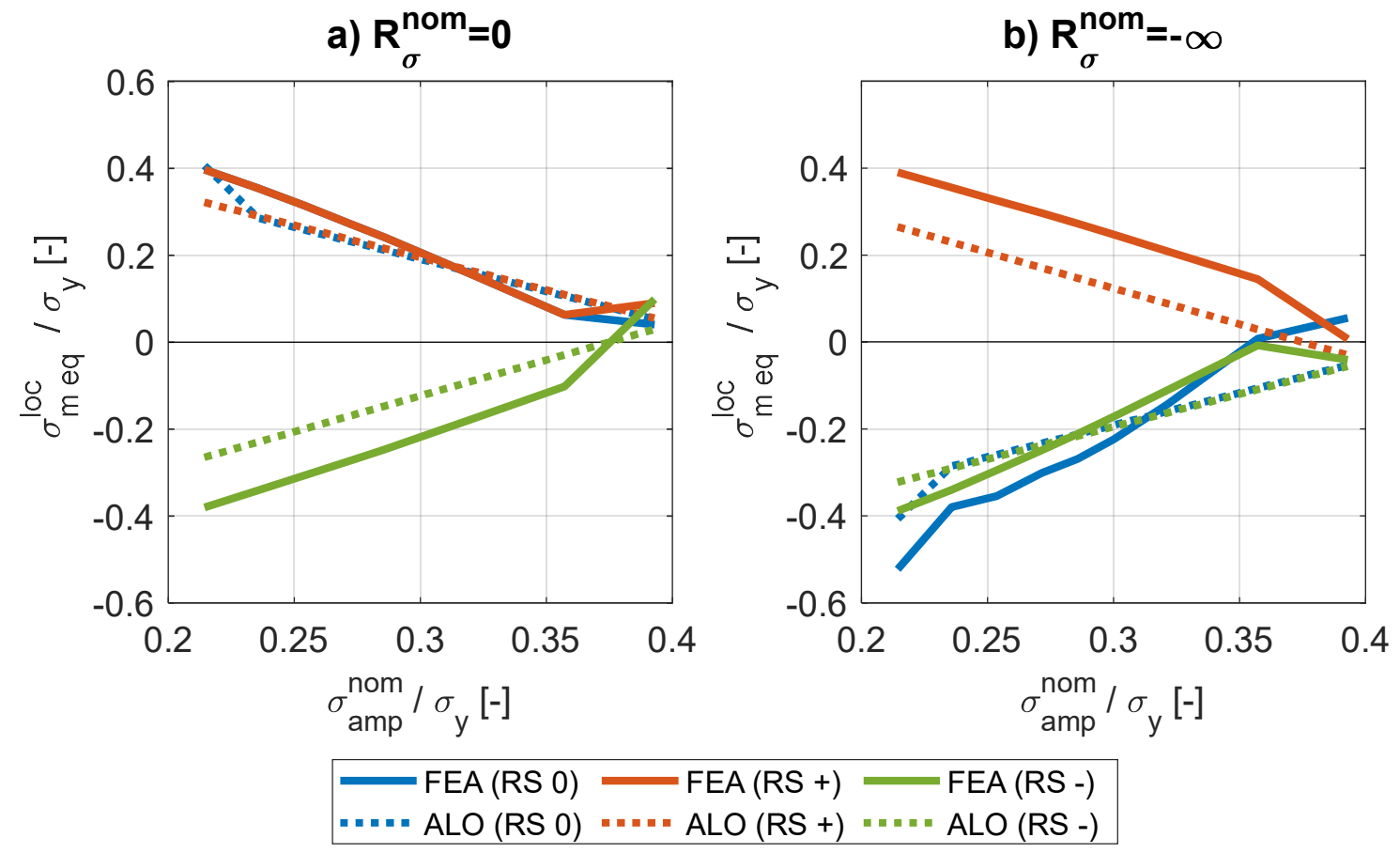

Figure 17: Predicted equivalent mean stress for the three initial residual stress states at $R_{\sigma}^{\text {nom }}=0$ (a) and $\boldsymbol{R}_{\boldsymbol{\sigma}}^{\text {nom }}=-\infty(\mathbf{b})$

The predicted equivalent maximum stress is shown in Figure 18. The predictions obtained through the ALO method and FEA are very similar. The initial residual stress has a similar effect on the maximum stress and on the mean stress predictions, i.e. 'RS +' and 'RS 0' specimens have the same predicted equivalent maximum stress under repeated tensile loadings while 'RS -' and 'RS 0' specimens have the same predicted equivalent maximum stress under repeated compressive loadings.

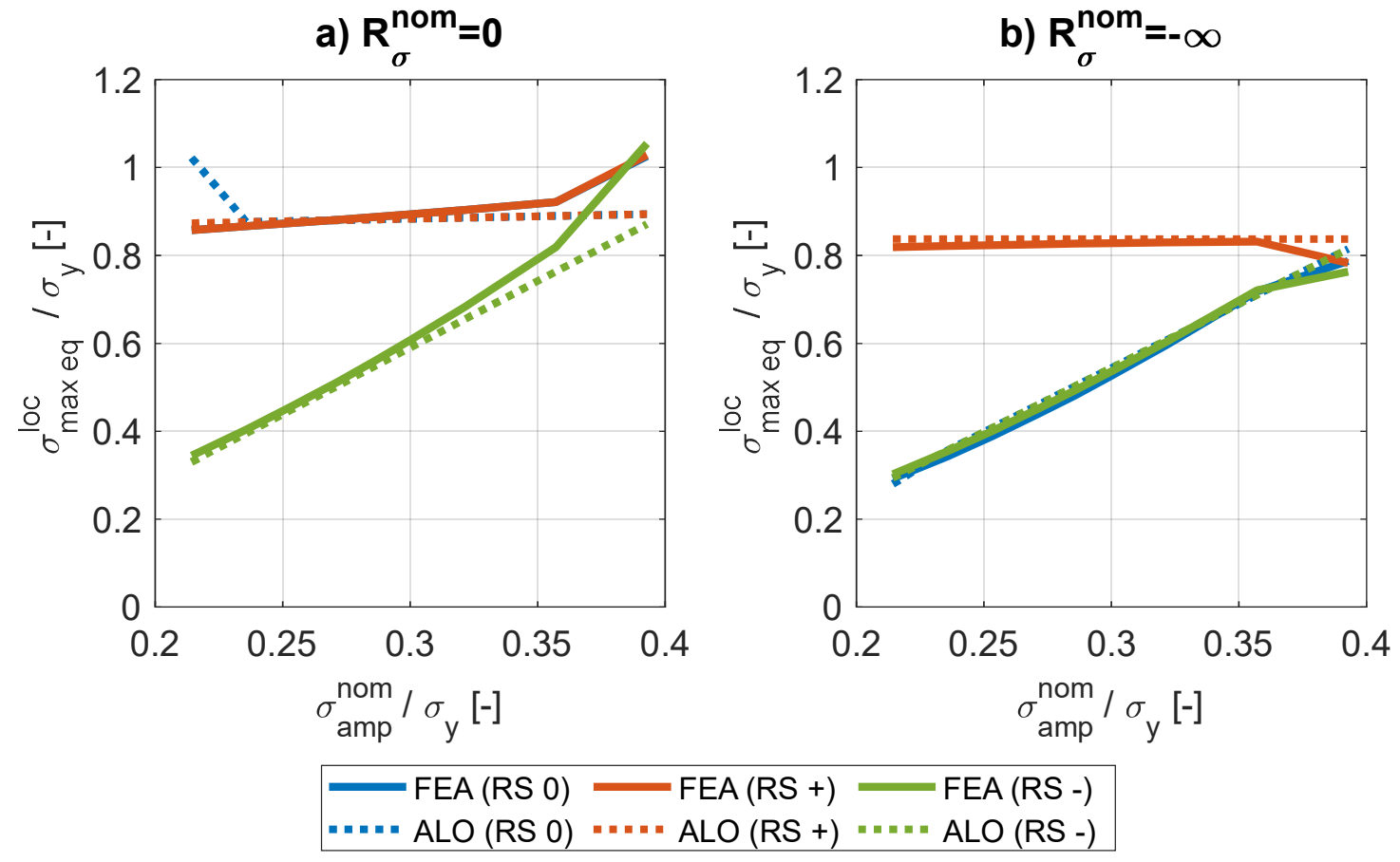

Figure 18: Predicted equivalent maximum stress for the three initial residual stress states at $R_{\sigma}^{\text {nom }}=0$ (a) and $\boldsymbol{R}_{\sigma}^{\text {nom }}=-\infty(\mathbf{b})$ 


\subsubsection{Fatigue life predictions results}

Predicted fatigue life curves using FEA and the ALO method with SWT and the modified Morrow's criteria are shown in Figure 19. Manson-Coffin-Basquin criterion results are not plotted as they are identical for all initial states and load ratios.

With the modified Morrow's criterion, the fatigue life predictions are the same with FEA and the ALO method, even if the mean stress predictions revealed some differences. This is explained by the fact that the largest error in the ALO method predictions is for high load levels where mean stress is almost equivalent to zero and thus has a low influence on the fatigue criterion. With the SWT criterion, as the maximum stress is used, it is not equivalent to zero and has a strong influence in the case of high load levels, where the confined-plasticity hypothesis is not verified, resulting in differences between FEA and ALO predictions for these high load levels (above $0.35 \sigma_{y}$, which corresponds to fatigue lifespans under 10,000 cycles). For fatigue lifespans above 10,000 cycles, fatigue life predictions obtained with FEA and the ALO method are identical. It can be pointed out that the ALO method divides the calculation time by a hundred without any loss in the fatigue life prediction accuracy for fatigue lifespans above 10,000 cycles.

It is interesting to observe that both criteria are able to predict the observed experimental trends, i.e. that in comparison to the reference stress-free initial state:

- initial tensile residual stresses have no effect under repeated tensile loadings whereas they reduce fatigue life under repeated compressive loading stresses,

- compressive residual stresses have no influence under repeated compressive loadings whereas they increase fatigue life under repeated tensile loadings.

Finally, predicted fatigue lives vs. experimental fatigue lives are plotted in a log-log graph (Figure 20). It appears clearly in Figure 20a that, with the MCB criterion, where the effect of the initial stress state or that of the load ratio is not taken into account, there is a bias in the prediction leading to non-conservative predictions for fatigue lifespans above 20,000 cycles with positive mean stress.

If the Smith-Watson-Topper criterion is used (Figure 20b), the load ratio and initial state effects are overestimated, leading to non-conservative predictions for mean compressive stress specimens.

The modified Morrow's criterion (Figure 20c) gives the best agreement between experimental and prediction data as all dots are homogeneously distributed along the perfect prediction line (in black). 

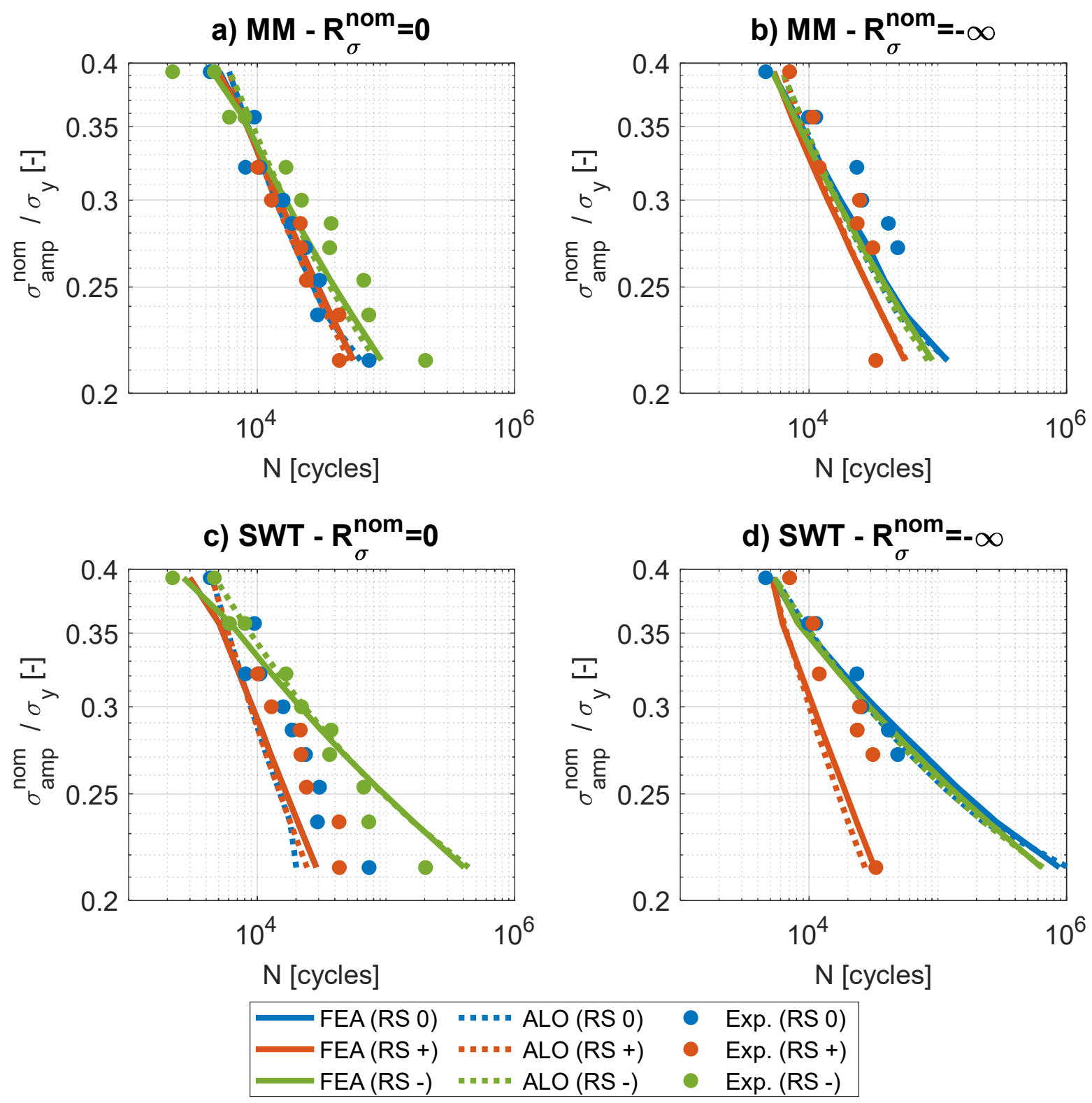

Figure 19 : Fatigue life prediction obtained with SWT and the modified Morrow's criteria at $R_{\sigma}^{n o m}=0$ and $\boldsymbol{R}_{\boldsymbol{\sigma}}^{\text {nom }}=-\infty$ 

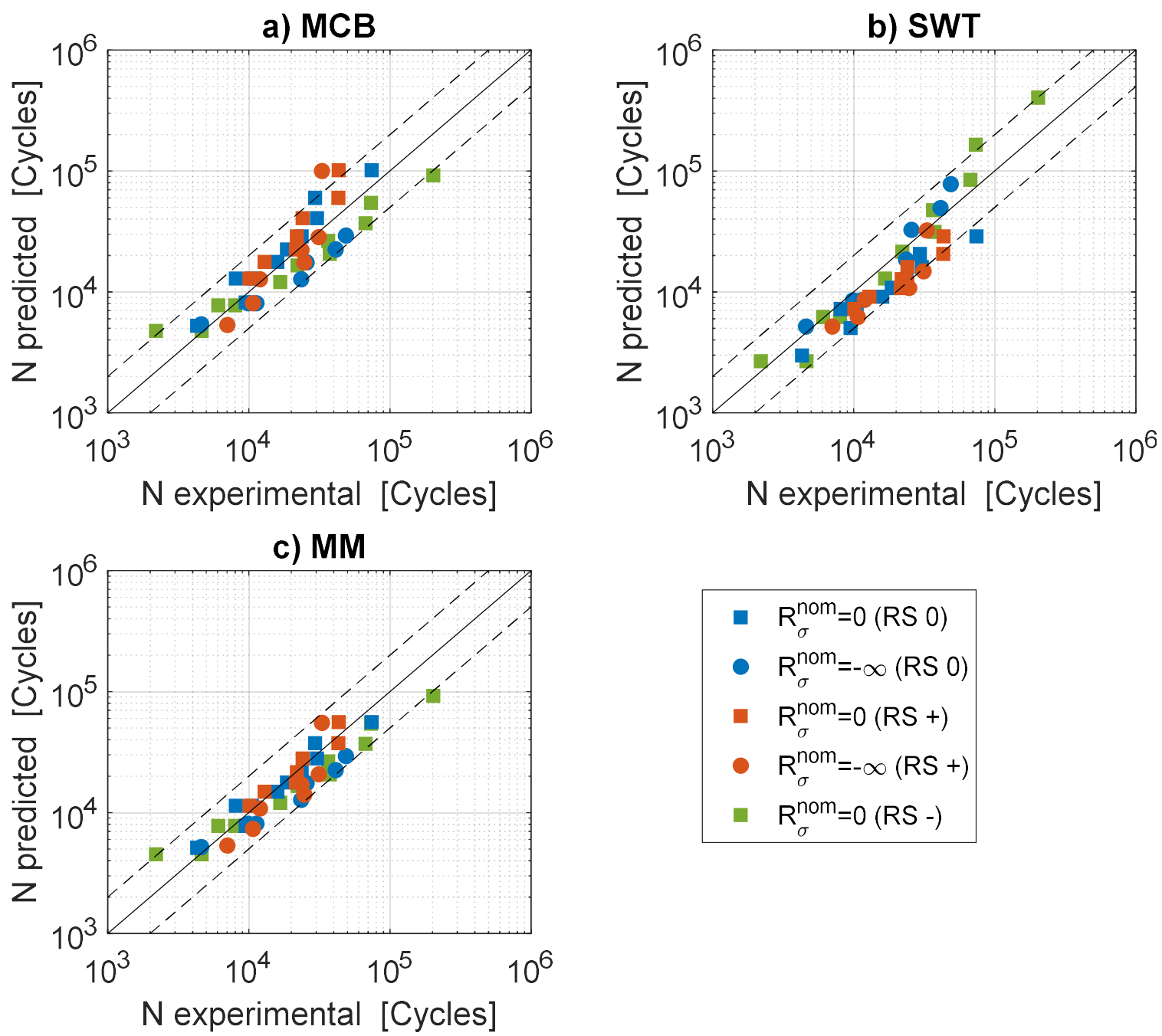

Figure 20 : Experimental vs. predicted fatigue life for the three initial residual stress states and the two load ratios with a) MCB, b) modified Morrow's and c) Smith-Watson-Topper criteria

\section{Conclusion}

This study's main objective is to assess the lifespan prediction ability of the adjustable localisation operator method for the low-cycle fatigue design of notched components under different load ratios and for different initial residual stress states. To obtain experimental validation data, the influence of two initial stress states was compared to initially residual stress-free specimens with the following observations:

- Under repeated tensile loadings, all specimens exhibit compressive residual stresses after one cycle. For fatigue lifespans above 10,000 cycles, specimens with initial residual tensile stresses (denoted 'RS +') and stress-free (denoted 'RS 0') have a positive mean stress that reduces fatigue lifespans in comparison to specimens with initial residual compressive stresses (denoted 'RS -') that have a negative mean stress. 
- Under repeated compressive loadings, all specimens exhibit tensile residual stresses after one cycle. For fatigue lifespans above 10,000 cycles, 'RS -' and 'RS 0' specimens have a negative mean stress that increases fatigue lifespans in comparison to ' $\mathrm{RS}+$ ' specimens that have a positive mean stress.

- For fatigue lifespans under 10,000 cycles, the initial stress influence disappears and similar fatigue lifespans are obtained for all initial states.

- The load ratio has an influence on fatigue lifespans of 'RS 0' specimens but not on specimens with initial residual stresses.

FEA was used to simulate residual stress fields that were validated through XRD stress analysis. The ALO method was also used to introduce residual stresses at the critical point. The cyclic behaviour was simulated with both methods to obtain the stabilised multiaxial stress-strain curves. An intermediate validation of the residual stress and of the strain amplitude was performed, showing that both FEA and the ALO method are able to predict the experimentally observed trends. It was also observed that neither the load ratio nor the initial state influences the strain amplitude, which implies that the MCB ratio is not able to predict the observed lifespans differences. The Smith-Watson-Topper criterion and a modified version of Morrow's criterion were used. Both these criteria can translate the influence of the load ratio or the initial state influence on the fatigue lifespans. However, it was shown that the SWT criterion overestimates this influence, leading to non-conservative predictions for compressive stress states under repeated tensile loadings. With the modified Morrow's criterion, the predicted lifespans are close to the experimental lifespans, which proves that it can correctly take the load ratio and the residual stress state influence into account.

In this design chain, the volume effect is directly taken into account through the calibration of the MCB criterion parameters for a single fatigue test. Further work will include the use of a probabilistic approach combined with a classic identification approach that avoids the need for a calibration test on the tested structure.

\section{Acknowledgements}

The authors would like to thank the French Armed Forces Ministry and the Defence Innovation Agency (AID) for their financial support of this work. 


\section{References}

[1] S. R. Thompson, J. J. Ruschau, and T. Nicholas, "Influence of residual stresses on high cycle fatigue strength of Ti-6Al-4V subjected to foreign object damage," Int. J. Fatigue, vol. 23, pp. 405-412, Jan. 2001, doi: 10.1016/S0142-1123(01)00166-9.

[2] J.-C. Kim, S.-K. Cheong, and H. Noguchi, "Residual stress relaxation and low- and high-cycle fatigue behavior of shot-peened medium-carbon steel," Int. J. Fatigue, vol. 56, pp. 114-122, Nov. 2013, doi: 10.1016/j.ijfatigue.2013.07.001.

[3] D. Paquet, J. Lanteigne, M. Bernard, and C. Baillargeon, "Characterizing the effect of residual stresses on high cycle fatigue (HCF) with induction heating treated stainless steel specimens," Int. J. Fatigue, vol. 59, pp. 90-101, Feb. 2014, doi: 10.1016/j.ijfatigue.2013.09.011.

[4] R. Eriksson, J. Moverare, and Z. Chen, "A low cycle fatigue life model for a shot peened gas turbine disc alloy," Int. J. Fatigue, vol. 124, pp. 34-41, Jul. 2019, doi: 10.1016/j.ijfatigue.2019.02.034.

[5] K. A. Soady, B. G. Mellor, J. Shackleton, A. Morris, and P. A. S. Reed, "The effect of shot peening on notched low cycle fatigue," Mater. Sci. Eng. A, vol. 528, no. 29, pp. 8579-8588, Nov. 2011, doi: 10.1016/j.msea.2011.08.003.

[6] T. N. Chakherlou and J. Vogwell, "The effect of cold expansion on improving the fatigue life of fastener holes," Eng. Fail. Anal., vol. 10, no. 1, pp. 13-24, 2003.

[7] W. Werchniak, "Effect of prestress on low-cycle fatigue," Eng. Fract. Mech., vol. 4, pp. 841-851, 1972.

[8] R. K. Nalla, "On the influence of mechanical surface treatments-deep rolling and laser shock peeningon the fatigue behavior of Ti-6Al-4V at ambient and elevated temperatures," Mater. Sci. Eng. A, vol. 355, no. 1-2, pp. 216-230, Aug. 2003, doi: 10.1016/S0921-5093(03)00069-8.

[9] H. Neuber, "Theory of Stress Concentration for Shear-Strained Prismatical Bodies With Arbitrary Nonlinear Stress-Strain Law," J. Appl. Mech., vol. 28, no. 4, pp. 544-550, Dec. 1961, doi: 10.1115/1.3641780.

[10] K. Molski and G. Glinka, "A method of elastic-plastic stress and strain calculation at a notch root," Mater. Sci. Eng., vol. 50, no. 1, pp. 93-100, Sep. 1981.

[11] M. Hoffmann and T. Seeger, "A Generalized Method for Estimating Multiaxial Elastic-Plastic Notch Stresses and Strains, Part 1: Theory," J. Eng. Mater. Technol., vol. 107, no. 4, pp. 250-254, Oct. 1985. 
[12] E. K. Walker, "MULTIAXIAL STRESS-STRAIN APPROXIMATIONS FOR NOTCH FATIGUE BEHAVIORS.," J. Test. Eval., vol. 5, no. 2, pp. 106-113, 1977.

[13] A. Moftakhar, A. Buczynski, and G. Glinka, "Calculation of elasto-plastic strains and stresses in notches under multiaxial loading," Int. J. Fract., vol. 70, no. 4, pp. 357-373, Dec. 1994, doi: 10.1007/BF00032453.

[14] A. Buczynski and G. Glinka, "An analysis of elasto-plastic strains and stresses in notched bodies subjected to cyclic non-proportional loading paths," Eur. Struct. Integr. Soc., vol. 31, no. C, pp. 265-283, 2003.

[15] R. J. McDonald and D. F. Socie, "A technique to estimate the local multiaxial elastic-plastic behavior from a purely elastic solution," Eng. Fract. Mech., vol. 78, no. 8, pp. 1696-1704, May 2011, doi: 10.1016/j.engfracmech.2010.12.001.

[16] D. Ye, O. Hertel, and M. Vormwald, "A unified expression of elastic-plastic notch stress-strain calculation in bodies subjected to multiaxial cyclic loading," Int. J. Solids Struct., vol. 45, no. 24, pp. 6177-6189, Dec. 2008, doi: 10.1016/j.ijsolstr.2008.07.012.

[17] R. Desmorat, "Fast estimation of localized plasticity and damage by energetic methods," Int. J. Solids Struct., vol. 39, no. 12, pp. 3289-3310, Jun. 2002.

[18] J. Zarka, J. J. Engel, and G. Inglebert, “On a simplified inelastic analysis of structures,” Nucl. Eng. Des., vol. 57, no. 2, pp. 333-368, May 1980, doi: 10.1016/0029-5493(80)90111-9.

[19] H. Hübel et al., "Performance study of the simplified theory of plastic zones and the Twice-Yield method for the fatigue check," Int. J. Press. Vessels Pip., vol. 116, pp. 10-19, Apr. 2014, doi: 10.1016/j.ijpvp.2014.01.003.

[20] P.-M. Lesne and S. Savalle, “An efficient cycles jump technique for viscoplastic structure calculations involving large number of cycles," ONERA TP No 1989-138, p. 13, 1989.

[21] D. Cojocaru and A. M. Karlsson, "A simple numerical method of cycle jumps for cyclically loaded structures," Int. J. Fatigue, vol. 28, no. 12, pp. 1677-1689, Dec. 2006, doi: 10.1016/j.ijfatigue.2006.01.010.

[22] N. Maouche, M. H. Maitournam, and K. Dang Van, "On a new method of evaluation of the inelastic state due to moving contacts," Wear, vol. 203-204, pp. 139-147, Mar. 1997, doi: 10.1016/S00431648(96)07428-5.

[23] J. D. Eshelby and R. E. Peierls, "The determination of the elastic field of an ellipsoidal inclusion, and related problems," Proc. R. Soc. Lond. Ser. Math. Phys. Sci., vol. 241, no. 1226, pp. 376-396, Aug. 1957.

[24] M. Sauzay, "Effets de surface et d'anisotropie en fatigue multiaxiale," Thèse de doctorat, Paris 6, 2000. 
[25] A. Darlet and R. Desmorat, "Stress triaxiality and Lode angle along surfaces of elastoplastic structures," Int. J. Solids Struct., vol. 67-68, pp. 71-83, Aug. 2015, doi: 10.1016/j.ijsolstr.2015.03.006.

[26] T. Herbland, G. Cailletaud, and S. Quilici, "Evaluation of local stress and strain state at notch root by means of a new method valid for multiaxial random loadings," presented at the International conference on fracture, Ottawa, Jul. 2009.

[27] B. Levieil, C. Doudard, D. Thevenet, F. Bridier, A. Ezanno, and S. Calloch, “An original simplified method based on the use of an adjustable localization operator for low-cycle fatigue life predictions in the case of confined plasticity," Theor. Appl. Fract. Mech., vol. 104, p. 102383, 2019, doi: https://doi.org/10.1016/j.tafmec.2019.102383.

[28] J. Lemaitre and J.-L. Chaboche, Mechanics of Solid Materials. Cambridge University Press, 1994.

[29] J. L. Chaboche, "Constitutive equations for cyclic plasticity and cyclic viscoplasticity," Int. J. Plast., vol. 5, no. 3, pp. 247-302, 1989, doi: 10.1016/0749-6419(89)90015-6.

[30] J. L. Chaboche, "On some modifications of kinematic hardening to improve the description of ratchetting effects," Int. J. Plast., vol. 7, no. 7, pp. 661-678, 1991, doi: 10.1016/0749-6419(91)90050-9.

[31] W. Prager, "Recent Developments in the Mathematical Theory of Plasticity," J. Appl. Phys., vol. 20, no. 3, pp. 235-241, Mar. 1949, doi: 10.1063/1.1698348.

[32] P. J. Armstrong and C. O. Frederick, A mathematical representation of the multiaxial Bauschinger effect. Central Electricity Generating Board [and] Berkeley Nuclear Laboratories, Research \& Development Department, 1966.

[33] J. Raujol-Veillé, D. Thévenet, C. Doudard, S. Calloch, and H. Minnebo, "Rapid method for low cycle fatigue properties: thickness effect on the fatigue crack initiation life of welded joints," Fract. Eng. Mater. Struct., vol. 38, pp. 1492-1506, 2015.

[34] E. Voce, "A practical strain-hardening function," Metallurgica, vol. 51, pp. 219-226, 1955.

[35] G. Totten, M. Howes, and T. Inoue, Handbook of Residual Stress and Deformation of Steel. 2002.

[36] C. P. Stack and R. I. Stephens, "Effect of split-sleeve cold-expansion on the fatigue resistance of hot-rolled 1020 steel," Int. J. Fatigue, vol. 11, no. 5, pp. 327-334, Sep. 1989, doi: 10.1016/0142-1123(89)90058-3.

[37] B. Levieil, F. Bridier, C. Doudard, D. Thevenet, and S. Calloch, “User Influence on Two Complementary Residual Stress Determination Methods: Contour Method and Incremental X-Ray Diffraction," Exp. Mech., vol. 56, no. 9, pp. 1641-1652, Jul. 2016, doi: 10.1007/s11340-016-0189-3. 
[38] V. Hauk, "Structural and Residual Stress Analysis by Nondestructive Methods," in Structural and Residual Stress Analysis by Nondestructive Methods, Amsterdam: Elsevier Science B.V., 1997, p. iii.

[39] V. Savaria, F. Bridier, and P. Bocher, "Computational quantification and correction of the errors induced by layer removal for subsurface residual stress measurements," Int. J. Mech. Sci., vol. 64, no. 1, pp. 184-195, Nov. 2012, doi: 10.1016/j.ijmecsci.2012.07.003.

[40] S. Chaudhuri, J. Crump, P. A. S. Reed, and B. G. Mellor, "High-resolution 3D weld toe stress analysis and ACPD method for weld toe fatigue crack initiation," Weld. World, vol. 63, no. 6, pp. 1787-1800, Nov. 2019, doi: 10.1007/s40194-019-00792-3.

[41] M. E. Barkey, D. F. Socie, and K. J. Hsia, "A Yield Surface Approach to the Estimation of Notch Strains for Proportional and Nonproportional Cyclic Loading," J. Eng. Mater. Technol., vol. 116, no. 2, pp. 173-180, Apr. 1994, doi: 10.1115/1.2904269.

[42] R. Sethuraman and S. Viswanadha Gupta, "Evaluation of notch root elasto-plastic stress-strain state for general loadings using an elastic solution," Int. J. Press. Vessels Pip., vol. 81, no. 4, pp. 313-325, Apr. 2004, doi: 10.1016/j.ijpvp.2004.03.002.

[43] T. Herbland, "Une méthode de correction élastoplastique pour le calcul en fatigue des zones de concentration de contraintes sous chargement cyclique multiaxial non proportionnel," Thèse de doctorat, Ecole des Mines de Paris, 2009.

[44] M. Chouman, A. Gaubert, J. L. Chaboche, P. Kanouté, G. Cailletaud, and S. Quilici, "Elastic-viscoplastic notch correction methods," Int. J. Solids Struct., vol. 51, no. 18, pp. 3025-3041, Sep. 2014, doi: 10.1016/j.ijsolstr.2014.04.017.

[45] S. S. Manson, "Fatigue: A complex subject-Some simple approximations," Exp. Mech., vol. 5, no. 4, pp. 193-226, Jul. 1965.

[46] L. F. J. Coffin, "A StUdy OF THE EFFECTS OF CYCLIC THERMAL STRESSES ON A DUCTILE METAL," Knolls Atomic Power Lab., KAPL-853, Jun. 1953.

[47] S. Bentachfine, G. Pluvinage, J. Gilgert, Z. Azari, and D. Bouami, “Notch effect in low cycle fatigue," Int. J. Fatigue, vol. 21, no. 5, pp. 421-430, May 1999, doi: 10.1016/S0142-1123(99)00004-3.

[48] A. Wormsen, B. Sjödin, G. Härkegård, and A. Fjeldstad, "Non-local stress approach for fatigue assessment based on weakest-link theory and statistics of extremes," Fatigue Fract. Eng. Mater. Struct., vol. 30, no. 12, pp. 1214-1227, 2007, doi: 10.1111/j.1460-2695.2007.01190.x. 
[49] K. Smith, P. Watson, and T. H. Topper, "A Stress Strain Function for the Fatigue of Metals," NI Marls, vol. 5, no. 4, pp. 767-778, 1970.

[50] J. Morrow, “Cyclic Plastic Strain Energy and Fatigue of Metals," Intern. Frict. Damping Cycl. Plast., Jan. 1965, doi: 10.1520/STP43764S. 